\title{
The UVSQ-SAT/INSPIRESat-5 CubeSat Mission: First In-Orbit Measurements of the Earth's Outgoing Radiation
}

\author{
Mustapha Meftah ${ }^{1, *} \mathbb{0}$, Thomas Boutéraon ${ }^{1} \oplus$, Christophe Dufour ${ }^{1}$, Alain Hauchecorne ${ }^{1}$, Philippe Keckhut ${ }^{1}$, \\ Adrien Finance ${ }^{1,2}{ }^{1}$, Slimane Bekki ${ }^{1}$, Sadok Abbaki ${ }^{1}$, Emmanuel Bertran ${ }^{1}$, Luc Damé ${ }^{1}$, Jean-Luc Engler ${ }^{1}$, \\ Patrick Galopeau ${ }^{1}$, Pierre Gilbert ${ }^{1}$, Laurent Lapauw ${ }^{1}$, Alain Sarkissian ${ }^{1}{ }^{1}$, André-Jean Vieau ${ }^{1}$, Patrick Lacroix ${ }^{1}$, \\ Nicolas Caignard ${ }^{1}$, Xavier Arrateig ${ }^{1}$, Odile Hembise Fanton d'Andon ${ }^{2}$, Antoine Mangin ${ }^{2}$, Jean-Paul Carta ${ }^{3}$, \\ Fabrice Boust ${ }^{4}$, Michel Mahé ${ }^{5}$ and Christophe Mercier ${ }^{6}$
}

check for updates

Citation: Meftah, M.; Boutéraon, T.; Dufour, C.; Hauchecorne, A.; Keckhut, P.; Finance, A.; Bekki, S.; Abbaki, S.; Bertran, E.; Damé, L.; et al. The UVSQ-SAT/INSPIRESat-5 CubeSat Mission: First In-Orbit Measurements of the Earth's Outgoing Radiation. Remote Sens. 2021, 13, 1449. https://doi.org/ $10.3390 / \mathrm{rs} 13081449$

Academic Editor: Xander Wang

Received: 24 March 2021

Accepted: 5 April 2021

Published: 8 April 2021

Publisher's Note: MDPI stays neutral with regard to jurisdictional claims in published maps and institutional affiliations.

Copyright: (c) 2021 by the authors. Licensee MDPI, Basel, Switzerland. This article is an open access article distributed under the terms and conditions of the Creative Commons Attribution (CC BY) license (https:/ / creativecommons.org/licenses/by/ $4.0 /)$.
1 Université de Versailles Saint-Quentin-en-Yvelines, Université Paris-Saclay, Sorbonne Université (SU), CNRS, LATMOS, 11 Boulevard d'Alembert, 78280 Guyancourt, France; Thomas.Bouteraon@latmos.ipsl.fr (T.B.); Christophe.Dufour@latmos.ipsl.fr (C.D.); Alain.Hauchecorne@latmos.ipsl.fr (A.H.); Philippe.Keckhut@latmos.ipsl.fr (P.K.); Adrien.Finance@latmos.ipsl.fr (A.F.); Slimane.Bekki@latmos.ipsl.fr (S.B.); sadok.abbaki@latmos.ipsl.fr (S.A.); emmanuel.bertran@latmos.ipsl.fr (E.B.); Luc.Dame@latmos.ipsl.fr (L.D.); Jean-Luc.Engler@latmos.ipsl.fr (J.-L.E.); Patrick.Galopeau@latmos.ipsl.fr (P.G.); Pierre.Gilbert@latmos.ipsl.fr (P.G.); laurent.lapauw@latmos.ipsl.fr (L.L.); Alain.Sarkissian@latmos.ipsl.fr (A.S.); andre-jean.vieau@latmos.ipsl.fr (A.-J.V.); patrick.lacroix@latmos.ipsl.fr (P.L.); nicolas.caignard@latmos.ipsl.fr (N.C.); xavier.arrateig@latmos.ipsl.fr (X.A.)

2 ACRI-ST_CERGA, 10 Avenue Nicolas Copernic, 06130 Grasse, France; oha@acri-st.fr (O.H.F.d.); Antoine.Mangin@acri-st.fr (A.M.)

3 Carta-Rouxel, Campus de l'Innovation des Yvelines, 17 rue Albert Thomas, 78130 Les Mureaux, France; jp.carta@lexat.fr

4 ONERA, 8 Chemin de la Hunière, 91123 Palaiseau, France; fabrice.boust@onera.fr

5 Radio-Club de Saint-Quentin-en-Yvelines F6KRK, 1 bis av. des Frênes, 78180 Montigny le Bretonneux, France; mahe_michel@yahoo.fr

6 AMSAT-Francophone, 14 bis rue des Gourlis, 92500 Rueil Malmaison, France; christophe.mercier@amsat-f.org

* Correspondence: Mustapha.Meftah@latmos.ipsl.fr; Tel.: +33-1-80-28-51-79

\begin{abstract}
UltraViolet \& infrared Sensors at high Quantum efficiency onboard a small SATellite (UVSQSAT) is a small satellite at the CubeSat standard, whose development began as one of the missions in the International Satellite Program in Research and Education (INSPIRE) consortium in 2017. UVSQSAT is an educational, technological and scientific pathfinder CubeSat mission dedicated to the observation of the Earth and the Sun. It was imagined, designed, produced and tested by LATMOS in collaboration with its academic and industrial partners, and the French-speaking radioamateur community. About the size of a Rubik's Cube and weighing about $2 \mathrm{~kg}$, this satellite was put in orbit in January 2021 by the SpaceX Falcon 9 launch vehicle. After briefly introducing the UVSQ-SAT mission, this paper will present the importance of measuring the Earth's radiation budget and its energy imbalance and the scientific objectives related to its various components. Finally, the first in-orbit observations will be shown (maps of the solar radiation reflected by the Earth and of the outgoing longwave radiation at the top of the atmosphere during February 2021). UVSQ-SAT is one of the few CubeSats worldwide with a scientific goal related to climate studies. It represents a research in remote sensing technologies for Climate observation and monitoring.
\end{abstract}

Keywords: climate observation and monitoring; earth radiation budget; nanosatellite; IPCC

\section{Introduction}

UVSQ-SAT is a nanosatellite designed to observe the Sun and the Earth, mainly for observing essential climate variables. It allows, among other things, measurements of the solar radiation reflected by the Earth or outgoing shortwave radiation (OSR) and of 
the outgoing longwave radiation (OLR) at the top of the atmosphere (TOA). A detailed description of the UVSQ-SAT mission and its satellite is given by Meftah et al. (2020) [1]. The main technical and scientific goal is to implement an agile demonstrator allowing to perform measurements of the Earth's radiation balance at the TOA. The UVSQ-SAT mission will allow to validate the principle of several miniaturized technologies as a first step to accurately measure the Earth's energy imbalance (EEI) with a constellation of small satellites. Regarding the educational objectives, the UVSQ-SAT program seeks to promote the transmission and valorization of scientific and technical knowledge through the innovation. This one feeds the creation of value and allows the implementation of technological breakthroughs and the associated risk-taking, the "NewSpace", and technology transfer.

Developed from 2017, UVSQ-SAT is based on a CubeSat architecture [2,3], which represents a satellite format defined in 1999 by the California Polytechnic State University and Stanford University (USA). UVSQ-SAT was developed and implemented by LATMOS and its INSPIRE international partners. The INSPIRE consortium was formed in 2015, with the objectives of developing small satellites to perform science missions, building a project-based learning curriculum for space science and engineering, and establishing a supporting network of ground stations. UVSQ-SAT/INSPIRESat-5 fully meets these objectives. A representative mockup of the UVSQ-SAT satellite is provided in Figure 1 left.
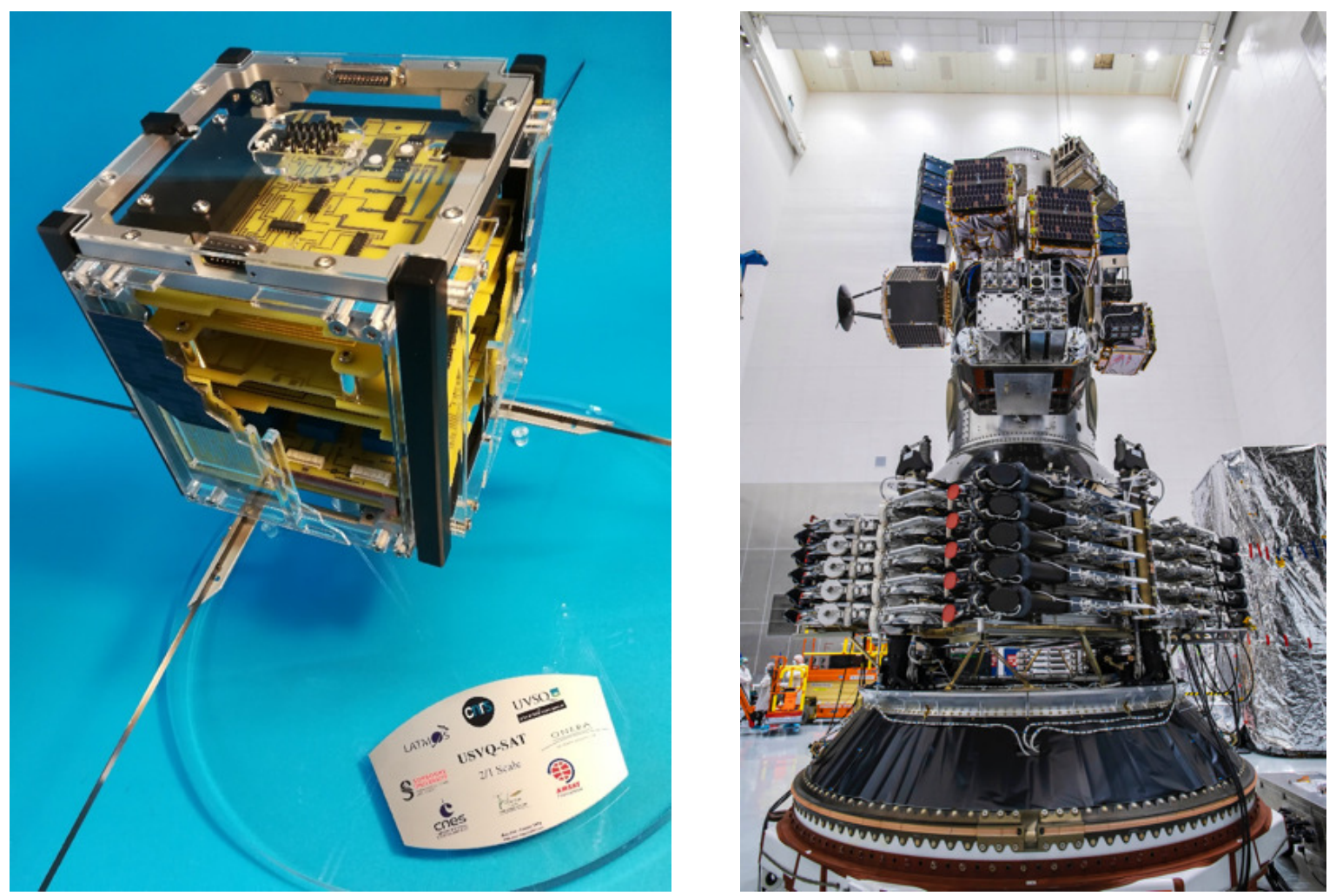

Figure 1. (Left) Representative mockup of the UVSQ-SAT satellite. (Right) Transporter 1 mission (SpaceX) with 143 commercial and government satellites on-board, including UVSQ-SAT. Credits: SpaceX.

Before being launched into space, a test campaign of the UVSQ-SAT CubeSat was carried out from August to October 2020. It typically involves several mechanical tests, electromagnetic compatibility (EMC) tests, calibration and performance tests, thermal vacuum and thermal balance tests, magnetic tests, and end to end tests. The satellite has been fully tested with French facilities (Figure 2) at LATMOS, at the Plateforme d'Intégration et de Tests (PIT) of the Observatoire de Versailles Saint-Quentin-en-Yvelines (OVSQ), at French space agency (CNES), and at the Office National d'Etudes et de Recherches Aérospatiales (ONERA). A successful mechanical testing campaign of the UVSQ-SAT CubeSat was mandatory to get a launch clearance. It involved quasi-static testing (test carried out with 
a static load of $15 \mathrm{~g}$ to simulate the acceleration of the launch vehicle), shock testing, as well as random vibration (test levels are shown in Figure 3 left). Random vibration was carried out to simulate the loads of the upper stages of the SpaceX Falcon 9 launcher and is the most severe test. Before and after each random axis test run, a resonance search (Figure 3 right) was done with a frequency sweep of low-level sinusoidal vibrations to characterize main resonant modes of the UVSQ-SAT CubeSat, to determine if the tests loads have changed the mechanical properties of the CubeSat (first eigenmode close to $418 \mathrm{~Hz})$, and to show possible deficiencies. Thermal bakeout was mandatory $\left(+60^{\circ} \mathrm{C}\right)$ for outgassing volatile materials of the CubeSat. A thermal vacuum cycling test (temperatures profile given in Figure 4) was also carried out to simulate the temperature conditions in orbit and to demonstrate that the CubeSat is able to survive, without loss of integrity or functionality. After performing all performances and environmental tests with success and confirmation of frequency coordination, UVSQ-SAT was ready to go in space.

(a)

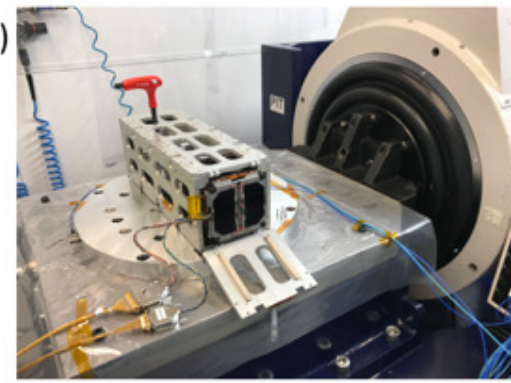

(d)

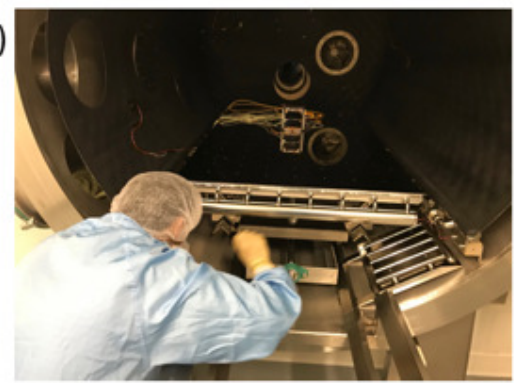

(b)

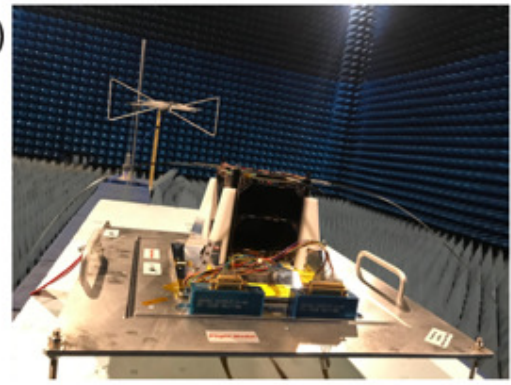

(e)

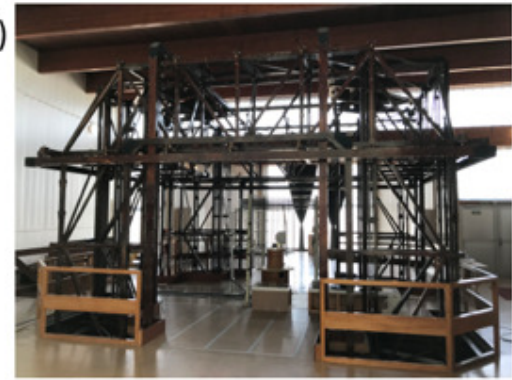

(c)

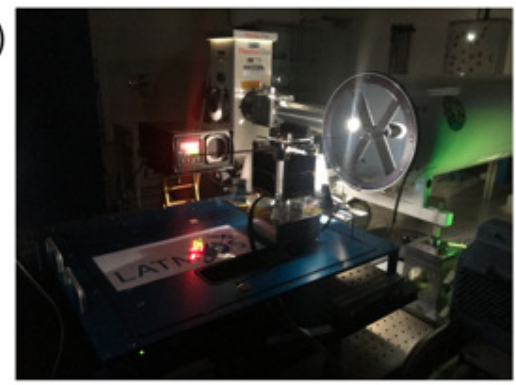

(f)

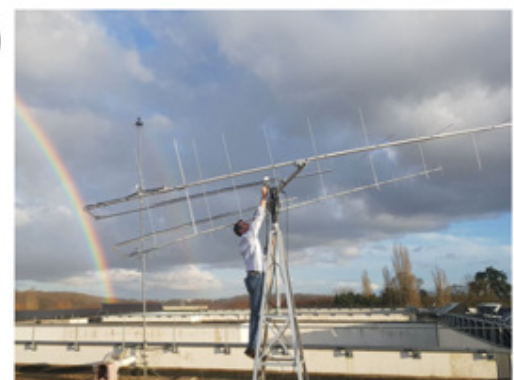

Figure 2. UVSQ-SAT environmental tests and calibrations carried out during the year 2020. (a) Vibration. (b) EMC tests. (c) Calibration with a Xenon lamp and a black body. (d) Thermal vacuum and thermal balance tests. (e) Magnetic cleanliness verification of the satellite. (f) End to end tests with the UHF/VHF LATMOS ground-based station (telemetry at 437.020 MHz, telecommand at 145.905 MHz).

UVSQ-SAT was launched on 24, January 2021 by the Falcon 9 rocket in the frame of the "Transporter 1" mission (Figure 1 right). Since then, the satellite is on a sun-synchronous orbit around the Earth at an altitude of about $533 \mathrm{~km}(515 \mathrm{~km}$ at perigee), an inclination of $97.5010^{\circ}$, an eccentricity of 0.0014455 , a right ascension at the ascending node of $128.4244^{\circ}$, and an argument at perigee of $94.1573^{\circ}$. The duration of an orbit is about $95.18 \mathrm{~min}$. The selected orbit presents eclipses, which allow to realize calibrations with observations towards the deep space or only towards the Earth.

This manuscript presents first UVSQ-SAT in-orbit measurements of the Earth's outgoing radiation. Section 2 presents the objectives of the UVSQ-SAT mission and the importance of measuring the Earth's radiation budget. The expected scientific requirements on the measurement of the Earth's energy imbalance will be presented. They are given for the UVSQ-SAT demonstrator and the future constellation (Terra-F) which must be disruptive. Section 3 presents the methods used to reconstruct the maps of the albedo and the OLR at the TOA. They are applicable to the observations by the UVSQ-SAT's instruments and the model used. Section 4 shows the first observations made by the UVSQ-SAT mission and the preliminary results. Section 5 highlights the perspectives related to this study and finally in Section 6, the conclusions are presented. 

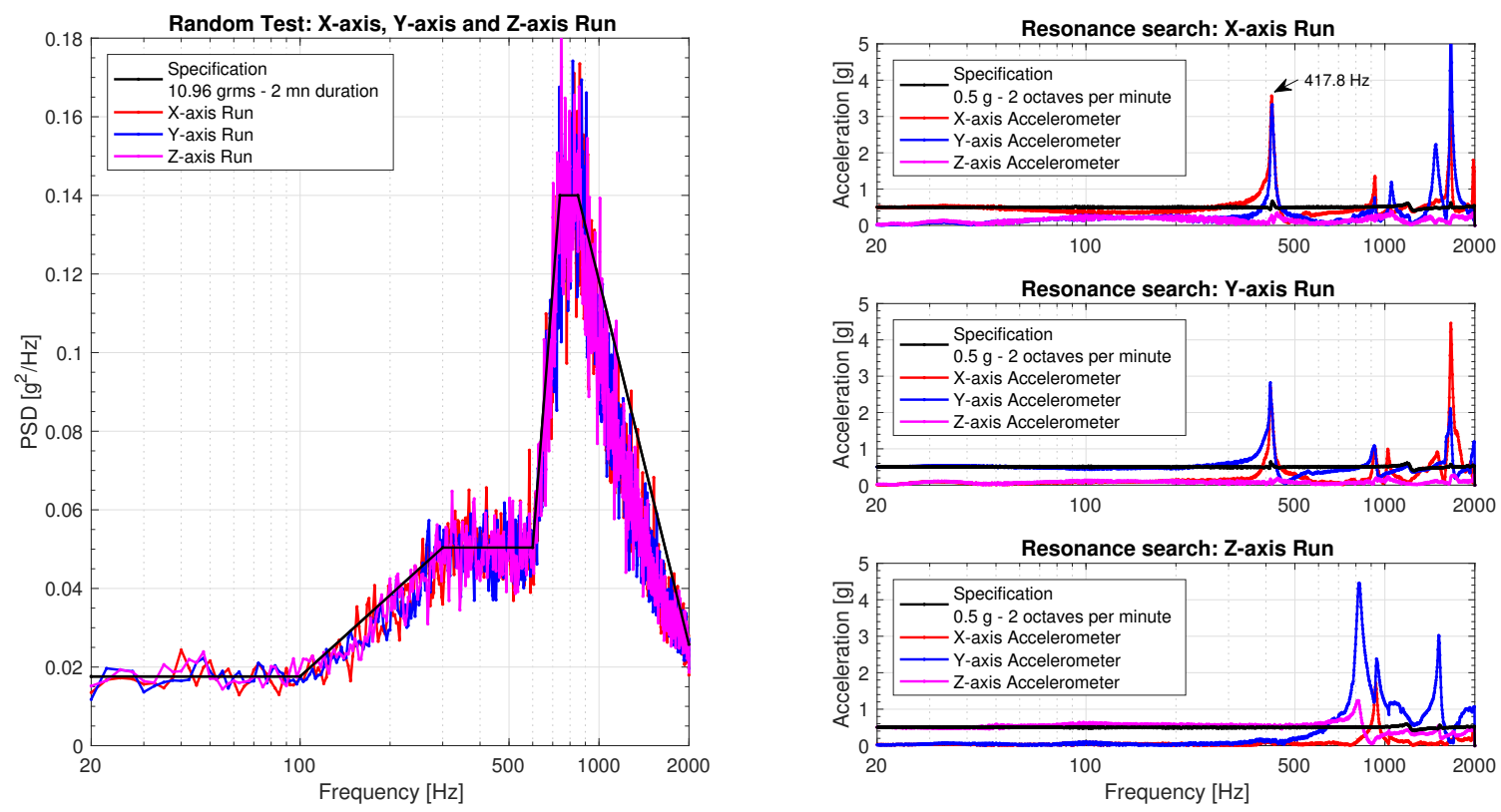

Figure 3. (Left) Random vibration profile was run in three orthogonal axes, referred as X, Y, Z. (Right) Resonance search carried out on UVSQ-SAT before and after each random run (September 2020).

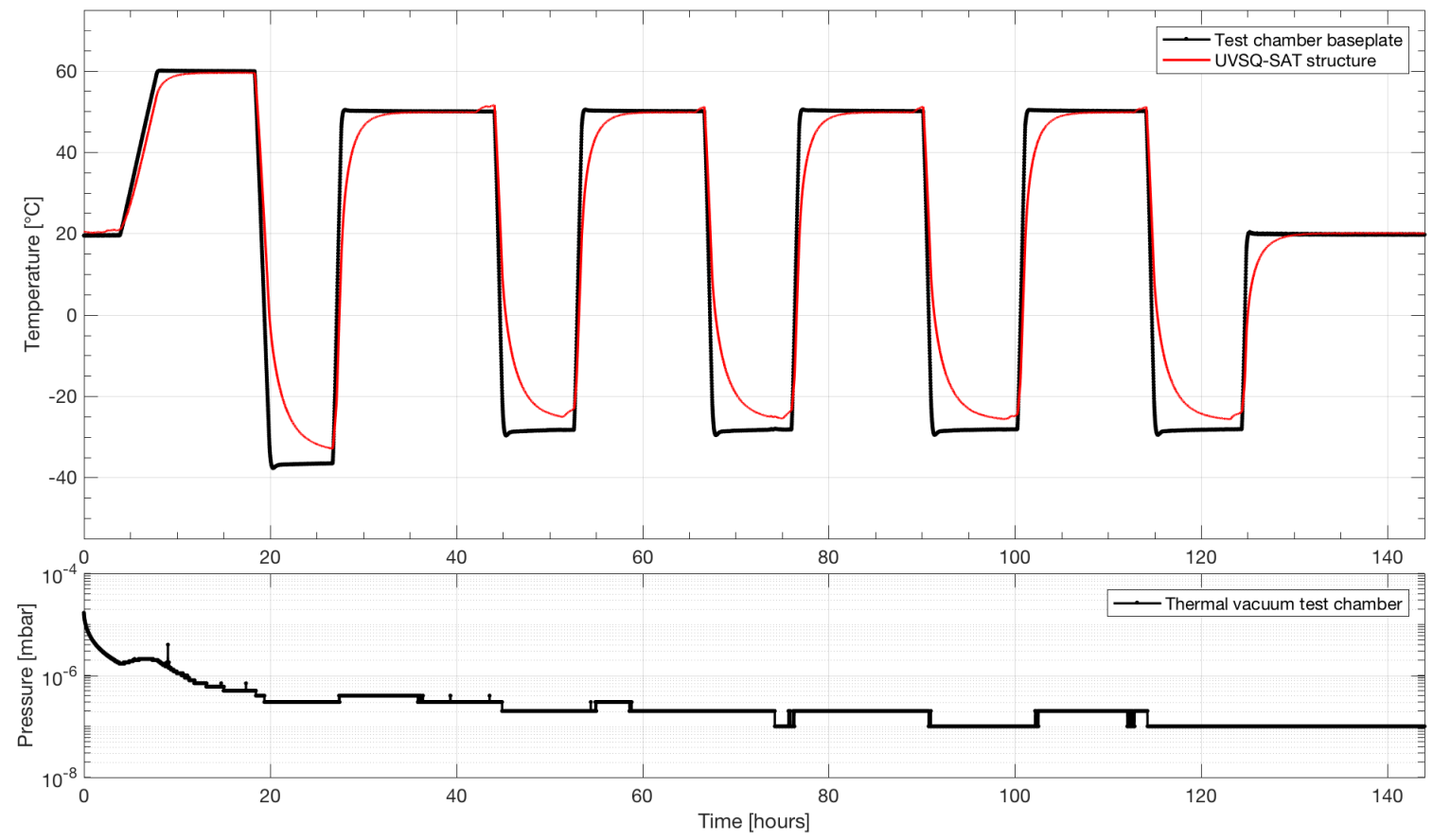

Figure 4. Profile of the UVSQ-SAT thermal vacuum cycling tests carried out in September 2020.

\section{Scientific Objectives and Requirements}

\subsection{Scientific Objectives}

One of the objectives of the UVSQ-SAT mission is the study of the Earth's energy budget (ERB) and its energy imbalance [1]. Climate is largely determined by its energy balance at the top of the atmosphere, which regulates the overall energy content of the Earth system, i.e., the atmosphere and ocean (IPCC, 2013). The system is heated by the absorption of incoming solar energy (shortwave) and is cooled by terrestrial infrared emission (longwave) to space. Almost 30\% of the incoming solar energy is not absorbed 
but reflected back to space. Human activities have led to increased levels of heat-trapping greenhouse gases (GHGs) in the atmosphere, with a decrease in the amount of terrestrial radiation that can escape, resulting in an Earth energy imbalance. As a result, the Earth system is heating up. The most obvious sign of this is the long-term increase in global surface temperatures, which increases outgoing terrestrial infrared emission and thus tends to restore the Earth's energy balance. However, as illustrated by the apparent slowdown in global surface warming observed between 1998 and 2012 ("climate hiatus"), global average surface temperature, with its large decadal internal variability, is certainly not the most appropriate indicator of the EEI and associated energy accumulation in the Earth system [4]. Since the EEI drives climate change, its continuous monitoring has been identified as a fundamental diagnostic for analyzing climate variability and anticipating future changes. Closing the Earth's energy balance is considered a key step to further improve our understanding of global climate change [5]. Ideally, the EEI should be measured continuously from space. To date, existing satellite instruments have not been able to measure solar and terrestrial radiative fluxes with sufficient accuracy to directly determine the absolute value of the EEI on their own, although measurements of relative changes in the EEI are much more reliable [6-8]. Note that determining EEI requires very accurate global radiative measurements because EEI results from the difference of several terms (incoming solar energy, reflected incoming solar energy, outgoing terrestrial infrared energy) that are two orders of magnitude higher than EEI. For this reason, satellite radiative flux data are often anchored in some way to ocean heat content data, as most of the excess energy does not accumulate at the surface or in the atmosphere, but is absorbed by the oceans [5,8]. Although ocean heat content is considered a better indicator of EEI, its global assessment remains challenging, mainly due to insufficient and inconsistent data coverage, and uncertainties in global scale extension $[9,10]$. Overall, this lack of accurate satellite measurements of EEI is a major problem because climate change is primarily a perturbation of the Earth's energy balance. In addition, satellite measurements of solar and terrestrial energy fluxes also represent critical constraints and benchmarks for the evaluation and improvement of climate models, including their representations of the radiative effects of clouds and aerosols (IPCC, 2013). Earth's radiation budget data are therefore a key source of information for distinguishing external from internal climate variability and for assessing the sensitivity of climate to different forcings (including volcanic eruptions, solar variability, and anthropogenic aerosols).

EEI determination represents a complex problem where the first relatively detailed balances of the energy exchanges of our planet and its atmosphere were published in 1997 by Kiehl and Trenberth [11]. An update of the ERB was completed by Stephens et al. [12] in 2012. Figure 5 illustrates the flow of energy through Earth's atmosphere. Table 1 provides ERB main contributions and EEI during the 2000-2010 period. Figure 5 shows how solar radiation warms our planet, and how this energy becomes temporarily trapped as it fluxes away from Earth's surface as longwave infrared radiation. This energy trap produces the greenhouse effect, which represents the main driver of global warming [13].

EEI is the difference between the total solar irradiance (TSI) and the OSR combined with the OLR thermally emitted. At the TOA, the EEI was $+0.58 \pm 0.15 \mathrm{Wm}^{-2}$ for the period 2005-2010 according to Hansen et al. (2011) [14]. It was estimated at $+0.60 \pm 0.40 \mathrm{Wm}^{-2}$ between 2000 and 2010 by Stephens et al. (2012) [12]. A recently published study by Von Schuckmann et al. (2020) [15] shows that the EEI is currently estimated to be $+0.87 \pm 0.12 \mathrm{Wm}^{-2}$ over the period 2010-2018 compared to $+0.47 \pm 0.10 \mathrm{Wm}^{-2}$ over the period 1971-2018. This positive EEI describes the excess of heat in the Earth system, mainly due to human activity. 


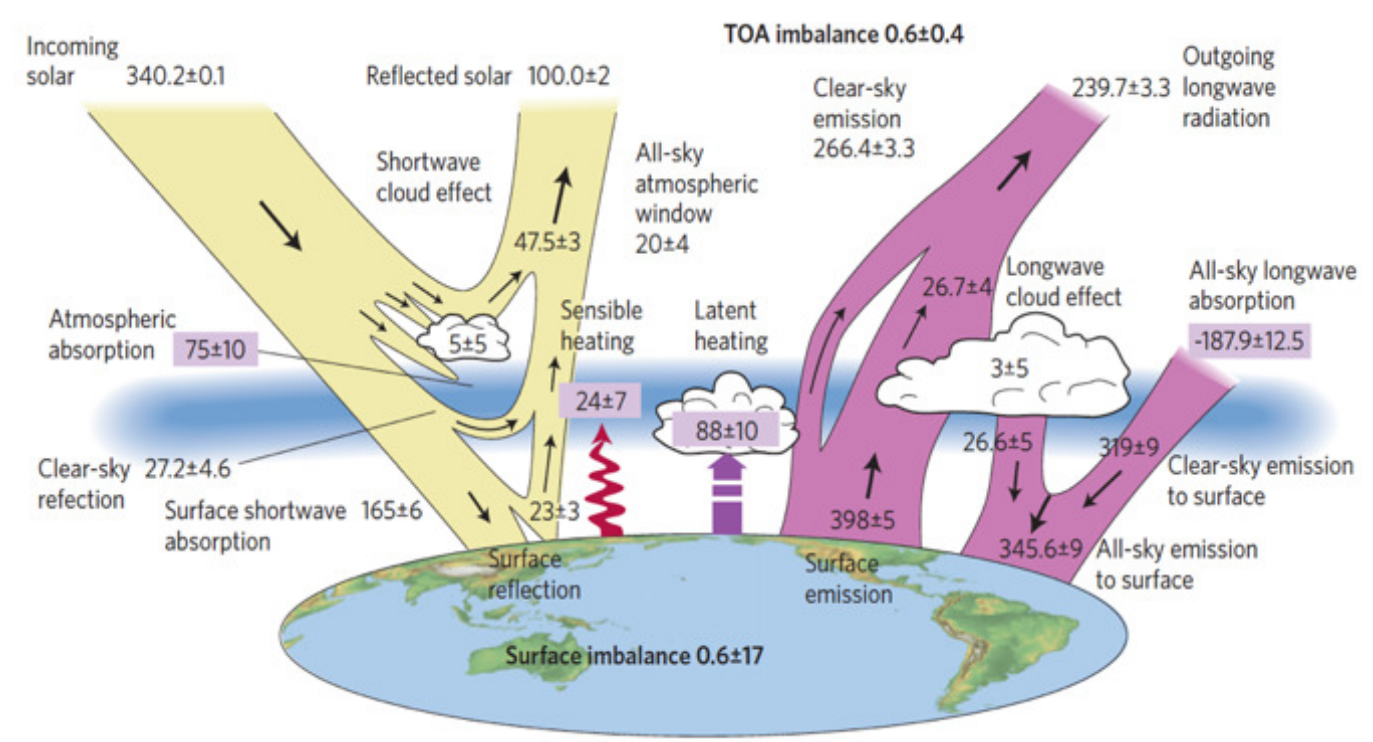

Figure 5. Radiation budget diagram of the Earth's atmosphere from Stephens et al. (2012) [12]. ERB for the period 2000-2010, where all flows are expressed in $\mathrm{Wm}^{-2}$.

Table 1. ERB main contributions and EEI during the period 2000-2010 from Stephens et al. (2012) [12].

\begin{tabular}{lll}
\hline Contributor/Imbalance & Acronym & Flux \\
\hline Incoming solar radiation & TSI $/ 4$ & $340.2 \pm 0.1 \mathrm{Wm}^{-2}$ \\
Outgoing shortwave radiation & OSR & $100.0 \pm 2.0 \mathrm{Wm}^{-2}$ \\
Outgoing longwave radiation & OLR & $239.7 \pm 3.3 \mathrm{Wm}^{-2}$ \\
\hline TOA Earth energy imbalance & EEI at TOA & $+0.6 \pm 0.4 \mathrm{Wm}^{-2}$ \\
Surface Earth energy imbalance & EEI at surface & $+0.6 \pm 17.0 \mathrm{Wm}^{-2}$ \\
\hline
\end{tabular}

Figure 6 shows the evolution of the OLR and the EEI (12-month rolling averages) over the last four decades. Changes in sea surface temperature (SST) during different phases of the El Niño Southern Oscillation (ENSO) and in cloud properties are often reflected in changes in OLR. The EEI strong variations correspond to volcanic eruptions that deposit aerosols in the stratosphere, thus cooling Earth by reflecting sunlight back to space. In 1982, El Chichón ejected million metric tons of sulfur dioxide into the stratosphere. In 1991, Mount Pinatubo represents the largest stratospheric disturbance since Krakatoa eruption in 1883, dropping global temperatures and increasing ozone depletion. Then, the global energy imbalance of the Earth is not constant over time. It depends on natural variability and the complexity of different climate forcings. The time series of measurements from the Clouds and the Earth's Radiant Energy System (CERES) instrument is compared to the ERA 5 model, which represents the fifth generation of atmospheric reanalyses of global climate from the European Centre for Medium-Range Weather Forecasts (ECMWF). These results highlight the impact of anthropogenic radiative forcing during a period where the TSI has decreased since 1980 and where solar cycle 24 (24th cycle since 1755) is much weaker than the previous two cycles. The various studies $[12,14,15]$ conclusively show the dominant role of the human-created greenhouse effect in driving global climate change. The EEI represents the most critical measure of the state of the Earth's climate. It sets expectations for future climate change (taking into account the Earth's inertia). 

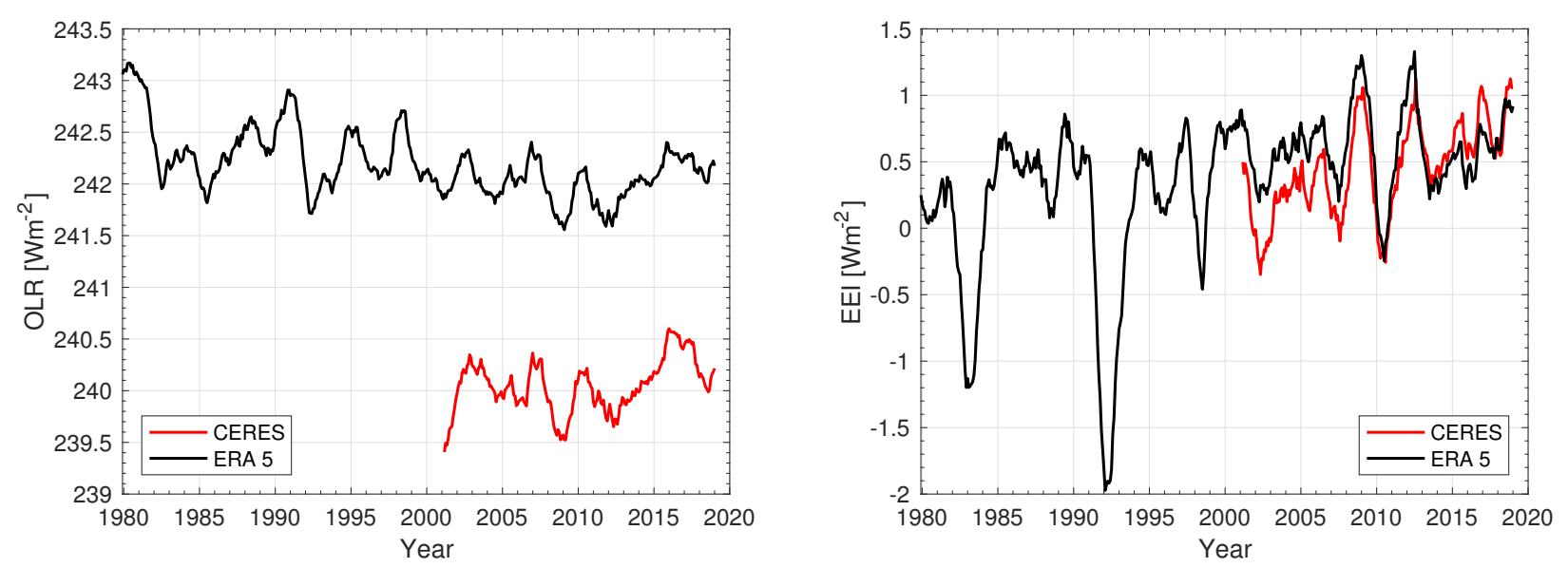

Figure 6. Time evolution of the OLR and the EEI from CERES measurements and the ERA 5 model.

The EEI represents the best approach to characterize global warming compared to other commonly used parameters ( $\mathrm{CO}_{2}$ concentration and Earth surface temperature). This highlights the importance of space-based missions that perform such measurements, including the UVSQ-SAT pathfinder mission associated with its possible small satellites constellation [1] named Terra-F. Further efforts to implement new space-based observing systems are more than necessary, as the EEI represents additional global warming that will occur without additional changes in radiative forcings. Direct measurements of changes in the EEI are of paramount importance in determining the rate of climate change on regional and global scales.

\subsection{Scientific Requirements and Uncertainties on EEI Measurements}

Accurately measuring the absolute value of the EEI at the TOA and its variability over time is still a scientific and technological challenge. The relevant scientific objective is to be able to detect any long-term global trend with a high accuracy (stability of at least $\pm 0.2 \mathrm{Wm}^{-2}$ per decade), but also to be able to obtain fine spatial (a few tens of $\mathrm{km}$ ) and high temporal resolutions (three hours as for weather forecasting) with an accuracy of a few $\mathrm{Wm}^{-2}$. With current technologies, we do not know if all these requirements are achievable with instruments on board satellites, but they are very important to better determine the changes.

To date, the best estimate of the EEI is obtained from the change in heat stored in the ocean, commonly referred as ocean heat content (OHC). However, the absorption of heat by the ocean acts as a "buffer". This causes the rate of surface warming to slow down. The OHC measurements made by the Argo automated floats are excellent, but do not provide answers to the "short term" dynamics. To solve this issue, we need fine spatial and temporal resolutions as previously stated. For this, we need a constellation of satellites with instruments that combine measurements with a narrow field of view (FOV) and a wide FOV. The key to solve this problem is related to the resolution of the diurnal variation, which depends on the physical parameterization of the models. The "long term" is associated with the convolution of quick processes and dynamic phenomena at longer temporal and spatial scales of the atmosphere-ocean system. Thus, the best strategy for measuring the EEI is to track the "long term" temporal evolution of the OHC since most of the excess heat (89\% over 1970-2018) is absorbed by the ocean [15]. These measurements must be combined with observations at the TOA using satellite-based instruments to provide "short term" information. Measurements with good spatio-temporal resolutions are crucial for advancing our understanding of climate change, as the radiative balance is driven in part by the radiative impacts of aerosols and clouds, which are highly spatially and temporally variable and are still relatively poorly quantified [16]. Currently, we do not know whether cloud-related changes will amplify, mitigate, or perhaps have only 
a small effect on the increase in the Earth's global temperature due to anthropogenic radiative forcings. Furthermore, we do not know the impact of radiative forcing related to anthropogenic aerosols that alter cloud properties. Global climate models have limitations with respect to these two issues. This highlights the importance of space-based missions to make accurate measurements with excellent spatio-temporal resolutions.

Observations are important to validate climate models and the magnitude of the energy imbalance at the TOA. Incident solar flux is an input to the model. The solar radiation reflected from the Earth or OSR and the OLR are calculated at the model level and must be compared to those measured. Table 2 summaries the expected science requirements for disruptive measurements of the energy imbalance components. In addition, some objectives of the UVSQ-SAT mission are presented. UVSQ-SAT is a science and technology demonstrator, one of whose objectives is to obtain an accurate short-term measurement of the EEI with a relative uncertainty that must be less than $\pm 1.0 \mathrm{Wm}^{-2}$ over the course of a year. The expected spatial resolution of the UVSQ-SAT measurements is in the order of $1000 \mathrm{~km}$. Forward, the method of Gristey et al. (2017) [17] will be used to improve the accuracy of the measurements thanks to a spherical harmonic analysis.

Table 2. Scientific requirements for the components of the Earth's radiation budget. High scientific relevance for a satellites constellation (Terra-F) and UVSQ-SAT expected performances.

\begin{tabular}{lllll}
\hline Requirements & Scientific Relevance & & & \\
\hline- & Absolute uncertainty & Stability per decade & Spatial resolution & Time resolution \\
\hline TSI & $\pm 0.54 \mathrm{Wm}^{-2}$ at $1 \sigma$ & $\pm 0.14 \mathrm{Wm}^{-2}$ at $1 \sigma$ & - & $24 \mathrm{~h}$ \\
OSR & $\pm 1.00 \mathrm{Wm}^{-2}$ at $1 \sigma$ & $\pm 0.10 \mathrm{Wm}^{-2}$ at $1 \sigma$ & $10-100 \mathrm{~km}$ & Diurnal cycle \\
OLR & $\pm 1.00 \mathrm{Wm}^{-2}$ at $1 \sigma$ & $\pm 0.10 \mathrm{Wm}^{-2}$ at $1 \sigma$ & $10-100 \mathrm{~km}$ & Diurnal cycle \\
\hline Requirements & UVSQ-SAT Performances & & & \\
\hline- & Absolute uncertainty & Stability per year & Spatial resolution & Time resolution \\
\hline TSI & - & - & - & - \\
OSR & $\pm 10 \mathrm{Wm}^{-2}$ at $1 \sigma$ & $\pm 5 \mathrm{Wm}^{-2}$ at $1 \sigma$ & $1000 \mathrm{~km}$ & 15 days \\
OLR & $\pm 10 \mathrm{Wm}^{-2}$ at $1 \sigma$ & $\pm 1 \mathrm{Wm}^{-2}$ at $1 \sigma$ & $1000 \mathrm{~km}$ & 15 days \\
\hline
\end{tabular}

\section{UVSQ-SAT Data Method and Map Reconstruction of the Variables (Observations and Model)}

\subsection{UVSQ-SAT Data Processing to Obtain Observation Time Series}

\subsubsection{Instrumental Equations of the Earth's Radiative Sensors}

The UVSQ-SAT scientific payload [1] consists of twelve miniaturized Earth's radiative sensors (ERS) based on thermopiles for monitoring the incoming solar radiation and the outgoing terrestrial radiation. Each face of the UVSQ-SAT satellite has two ERS sensors, which have different optical coatings (carbon nanotubes or optical solar reflector). The properties of the coatings were characterized in lab (solar absorption, hemispherical emissivity, bidirectional reflectance distribution function (BRDF)). The principle of these ERS sensors with their associated coatings is to convert thermal energy into electrical energy. The output voltage $(V)$ is passively induced from the thermopile proportional to the heat flux $\left(\mathrm{Wm}^{-2}\right)$ through the sensor or similarly the temperature gradient across the thin-film substrate and number of thermocouple junction pairs. The output voltage is conditioned by an electronic unit and converted into analog-to-digital units (ADU) and is read by the UVSQ-SAT onboard computer (OBC) thanks to a serial peripheral interface (SPI) bus, and stored by the OBC. Once data are retrieved, the ADU signals $S_{A D U}$ are 
converted into physical units to express the incident flux measurements $\Phi_{\text {in }}$ on an ERS sensor using the transfer function (Equation (1)):

$$
\Phi_{i n}=\left(\frac{S_{A D U}\left(T_{s}, T_{b}\right)-V_{A D U}^{r e f}\left(T_{b}\right)}{N_{s a m p}}+C_{1}\left(T_{s}, T_{b}\right)\right) \times \frac{1}{G\left(T_{b}\right)} \times \frac{1}{\operatorname{Sens}\left(T_{s}\right)}+C_{2}\left(T_{s}\right)
$$

where $V_{A D U}^{r e f}$ is a reference voltage, $N_{\text {samp }}$ is the number of samples for a measurement, $G\left(T_{b}\right)$ is the gain of the electronic unit, Sens is the sensitivity of the sensor (calibration in lab), $C_{1}$ and $C_{2}$ are corrective offsets, which depend on the temperature of the sensor. In the case of thermopiles, $C_{2}=-\epsilon \sigma T_{s}^{4} . \epsilon$ is the hemispherical emissivity of the thermopile coating and $T_{s}$ is the ERS sensor temperature. $T_{b}$ represents the temperature of the sensors electronic board.

The total incident flux $\left(\Phi_{i n}\right)$ on each ERS sensor is the sum of the solar incident flux, the planetary incident flux $\left(\Phi p_{i n}\right)$, and the albedo incident flux $\left(\Phi a_{i n}\right)$. The incident solar flux is considered to be known (TSI is measured precisely elsewhere). By combining information from two ERS sensors on the same face (sensor with carbon nanotubes (solar absorption close to 1) and sensor with optical solar reflector (solar absorption less that 0.1 )), we get the albedo $(a)$ of the planet and the outgoing longwave radiation (OLR) at a measurement point located in latitude and longitude on the world map (Equations (2) and (3) are given as example if a satellite face observes at the nadir):

$$
\begin{gathered}
\Phi p_{\text {in }}=\epsilon \times \mathrm{OLR} \times\left(\frac{R}{R+z_{\text {sat }}}\right)^{2} \\
\Phi a_{\text {in }}=\alpha \times a \times\left(\frac{R}{R+z_{\text {sat }}}\right)^{2} \times \cos (\xi) \times \mathrm{TSI} \times\left(\frac{1 a u}{d_{s}}\right)^{2}
\end{gathered}
$$

where $R$ is Earth's radius, $z_{\text {sat }}$ is the satellite altitude, $\alpha$ is the ERS (coating) solar absorption, $\xi$ is the solar zenith angle, $1 \mathrm{au}$ is one astronomical unit, and $d_{s}$ is the distance UVSQ-SAT-Sun.

During satellite eclipse periods, two ERS sensors on the same face measure only OLR, which allow to obtain direct measurements and inter-calibration of the sensors.

\subsubsection{Instrumental Equations of the Optical Sensors Based on Photodiodes}

The UVSQ-SAT scientific payload has also six photodiodes to measure the total solar irradiance and the outgoing shortwave radiation, and four additional photodiodes for observing the Sun (three measure the total solar irradiance and one measures the UV solar spectral irradiance in the Herzberg continuum). Each face of the satellite has at least one photodiode who observes external fluxes. A photodiode is a semiconductor p-n junction device that converts light into an electrical current. The resulting current is converted into ADU and stored by the UVSQ-SAT onboard computer. Once data are retrieved, the ADU signals $S p_{A D U}$ are converted into physical units to express the measurements $\Phi_{\text {pho }}$ using the transfer function (Equation (4)):

$\Phi_{\text {pho }}=\left(\frac{S p_{A D U}\left(T_{\text {pho }}, T_{b}\right)-V_{A D U}^{r e f}\left(T_{b}\right)}{N p_{\text {samp }}}+C p_{1}\left(T_{\text {pho }}, T_{b}\right)\right) \times \frac{1}{G_{p h o}\left(T_{b}\right)} \times \frac{1}{S_{\text {pho }}\left(T_{\text {pho }}\right)}$

where $N p_{\text {samp }}$ is the number of samples for a measurement, $G_{p h o}$ is the gain of the electronic unit, $S_{p h o}\left(T_{p h o}\right)$ is the responsivity of the photodiode (calibration done by the manufacturer), $C p_{1}$ is a corrective offset, which depends on the temperature of the photodiode. $T_{\text {pho }}$ is the satellite structure temperature close to the photodiode. 
For the six photodiodes that measure the total solar irradiance and the outgoing shortwave radiation, the albedo of the Earth can be obtained using an equation similar to that proposed in Equation (3).

\subsubsection{Methodology for Obtaining UVSQ-SAT Attitude and Position Time Series}

UVSQ-SAT has a new 3-axis accelerometer/gyroscope/compass (Teach' Wear (TW)) for providing satellite attitude estimation [1]. Using the TW observations, it is possible to achieve sufficient attitude estimation accuracy for a satellite using regular Kalman filter algorithm. Another way is to use a new method based on a multilayer perceptron network to determine the UVSQ-SAT satellite attitude [18].

Otherwise, we have a good knowledge of the UVSQ-SAT CubeSat position (latitude, longitude, altitude) according to the Two-Line Element sets (TLE) that are generally used to predict the position of a satellite. For each measurement carried-out by the instruments, we have its location on the world map. Figure 7 shows an example of ground track measurements location of the UVSQ-SAT satellite during February 2021, which represents the path on the surface of the Earth directly below the satellite's trajectory. The knowledge of the satellite position allows to calculate notably the solar zenith angle (from latitude, longitude, solar declination, Universal Time) and to rigorously locate the measurements area.

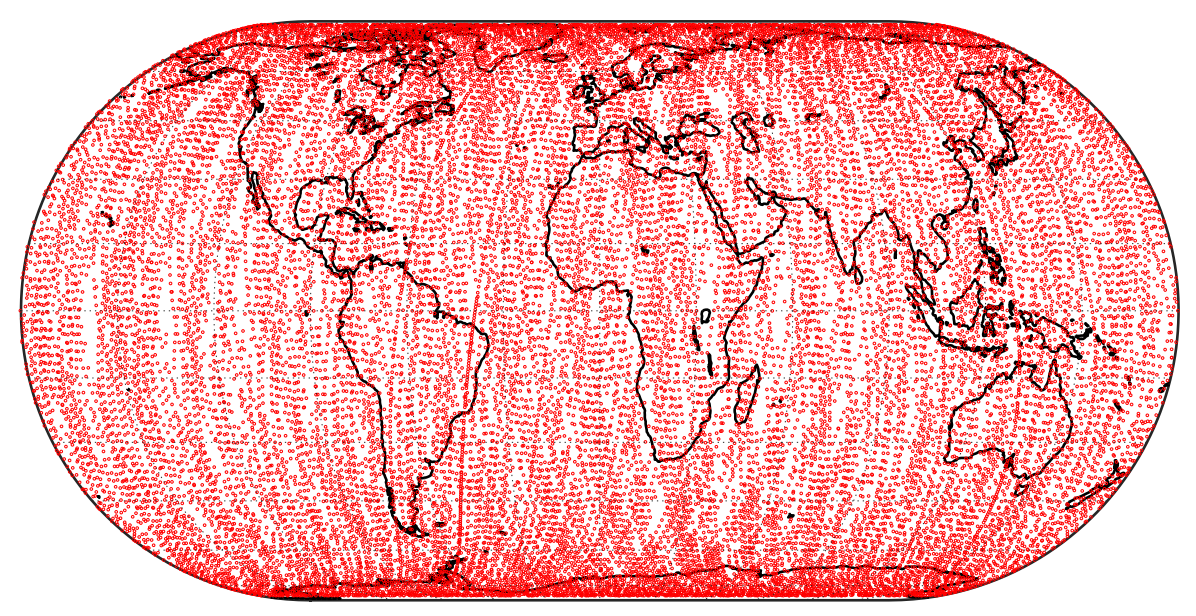

Figure 7. Location (latitude and longitude) of UVSQ-SAT observations (red colored dots on the world map) during the month of February 2021.

\subsection{Map Reconstruction Method from UVSQ-SAT Observation Time Series}

Time series of the albedo and the OLR at the TOA are obtained from the observations made by the dedicated sensors on-board UVSQ-SAT.

Physically, each measurement of these time series represents the integral of the signal of interest (OLR, albedo) and depends in practice on a large number of parameters among which the bidirectional reflectance distribution function of the Earth's surface, the opacity of the atmosphere, the spectral and angular sensitivities of the sensors and their FOV. In particular, concerning the opacity, it depends on factors such as aerosol composition, clouds, temperature or pressure.

In a first approach, we consider that each measurement results from the contribution of a Gaussian distribution $G\left(\theta_{i, j}\right)$ of points located at the surface of the Earth. Let the surface of the Earth modeled by a regular grid whose coordinates are expressed with latitude and longitude. Each pixel $(i, j)$ of the grid is defined by its longitude $\lambda_{i}$ and latitude $\phi_{j}$ coordinates and by its area $S_{i j}$ (Equation (5)):

$$
S_{i j}=R^{2} \times \cos \left(\phi_{j}\right) \Delta \lambda_{i} \Delta \phi_{j}
$$

where $\Delta \lambda_{i}, \Delta \phi_{j}$ are size in radians of the pixel at longitude $\lambda_{i}$ and latitude $\phi_{j}$. 
The satellite has a location $\lambda_{\text {sat }}, \phi_{\text {sat }}$ and an altitude $z_{\text {sat }}$. The angle $\theta_{i, j}$ at the center of the Earth (nadir) between the satellite and the pixel $(i, j)$ is given by Equation (6). The angle $\alpha_{i, j}$ between the nadir of the satellite and the pixel $(i, j)$ is given by Equation (7). The satellite elevation $\beta_{i, j}$ (complement of zenith angle) seen by the pixel $(i, j)$ is given by Equation (8).

$$
\begin{gathered}
\theta_{i, j}=\operatorname{acos}\left[\cos \left(\phi_{j}\right) \cos \left(\phi_{s a t}\right) \cos \left(\lambda_{i}-\lambda_{s a t}\right)+\sin \left(\phi_{j}\right) \sin \left(\phi_{\text {sat }}\right)\right] \\
\alpha_{i, j}=\operatorname{atan}\left(\frac{R \sin \left(\theta_{i, j}\right)}{z_{s a t}+R\left(1-\operatorname{acos}\left(\theta_{i, j}\right)\right)}\right) \\
\beta_{i, j}=\frac{\pi}{2}-\alpha_{i, j}-\theta_{i, j}
\end{gathered}
$$

The view angle $\Omega_{i, j}$ under which the pixel $(i, j)$ is seen by the satellite is given by Equations (9) and (10).

$$
\begin{array}{lll}
\Omega_{i, j}=S_{i j} z^{2} \cos \left(\alpha_{i, j}\right) \sin \left(\beta_{i, j}\right) & \text { if } & \beta_{i, j} \geq 0 \\
\Omega_{i, j}=0 & \text { if } & \beta_{i, j}<0
\end{array}
$$

Figure 8 represents the different angles between the satellite, the nadir, and the observation location. This latter location is seen by the satellite according to a Gaussian distribution $G\left(\theta_{i, j}\right)$, which is defined by Equation (11):

$$
G\left(\theta_{i, j}\right)=\exp \left(-\frac{\alpha^{2}}{2 \sigma^{2}}\right)
$$

with $\sigma$, the variance of the Gaussian. $\sigma$ is related to the FOV via $\sigma=\mathrm{FOV} / 2$. For example, for an average altitude of $540 \mathrm{~km}$ and a FOV of $135^{\circ}$, which are the characteristics of UVSQ-SAT, the diameter of the ground track is about $2600 \mathrm{~km}$.

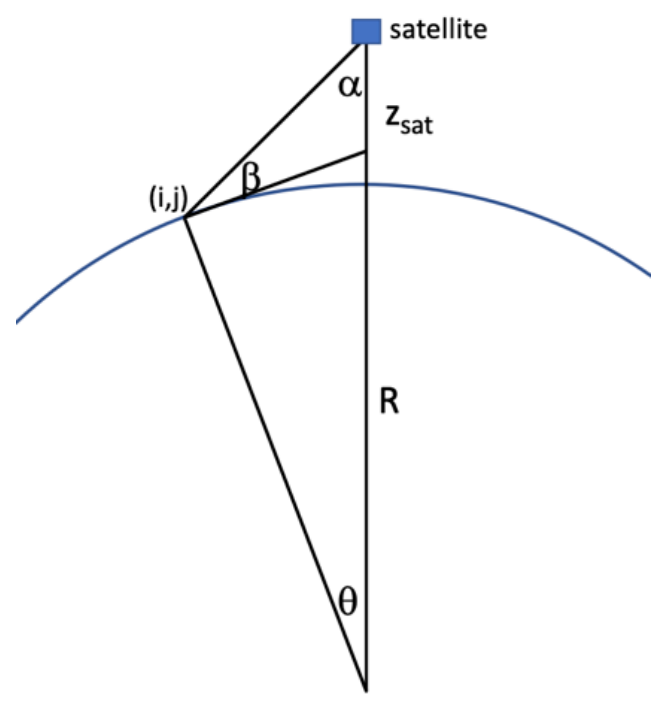

Figure 8. Visualization of the satellite in orbit, characteristic angles and pixel seen by the satellite. 
The observed flux by UVSQ-SAT $F_{\text {sat }}\left(\lambda_{\text {sat }}, \phi_{\text {sat }}\right)$ is given by (Equation (12)):

$$
F_{s a t}\left(\lambda_{s a t}, \phi_{s a t}\right)=\frac{\sum_{i, j} \Omega_{i, j} G_{i, j} F_{i, j}}{\sum_{i, j} \Omega_{i, j} G_{i, j}}
$$

Finally, to reconstruct the map of what was measured by UVSQ-SAT, i.e., $F_{\text {sat }}\left(\lambda_{\text {sat }}, \phi_{\text {sat }}\right)$, we calculate the functions $\Omega_{i, j}, G_{i, j}$ for the satellite track to find the flux $F_{i, j}$ associated with each pixel.

\subsection{Reconstruction Method of the ERA 5 Maps to Compare with the UVSQ-SAT Maps}

To compare the UVSQ-SAT measurements and a model (ERA 5), it is necessary to have similar inputs that means, i.e., to have the same observations time series (temporal) and similar FOV (spatial) at TOA.

Figure 9 shows the monthly averaged maps of the albedo and the OLR in February 2021 (for the ERA 5 model). All data of the ERA 5 model were used to obtain these maps (temporal resolution of $1 \mathrm{~h}$ and a pixel resolution of $721 \times 1440$ ).
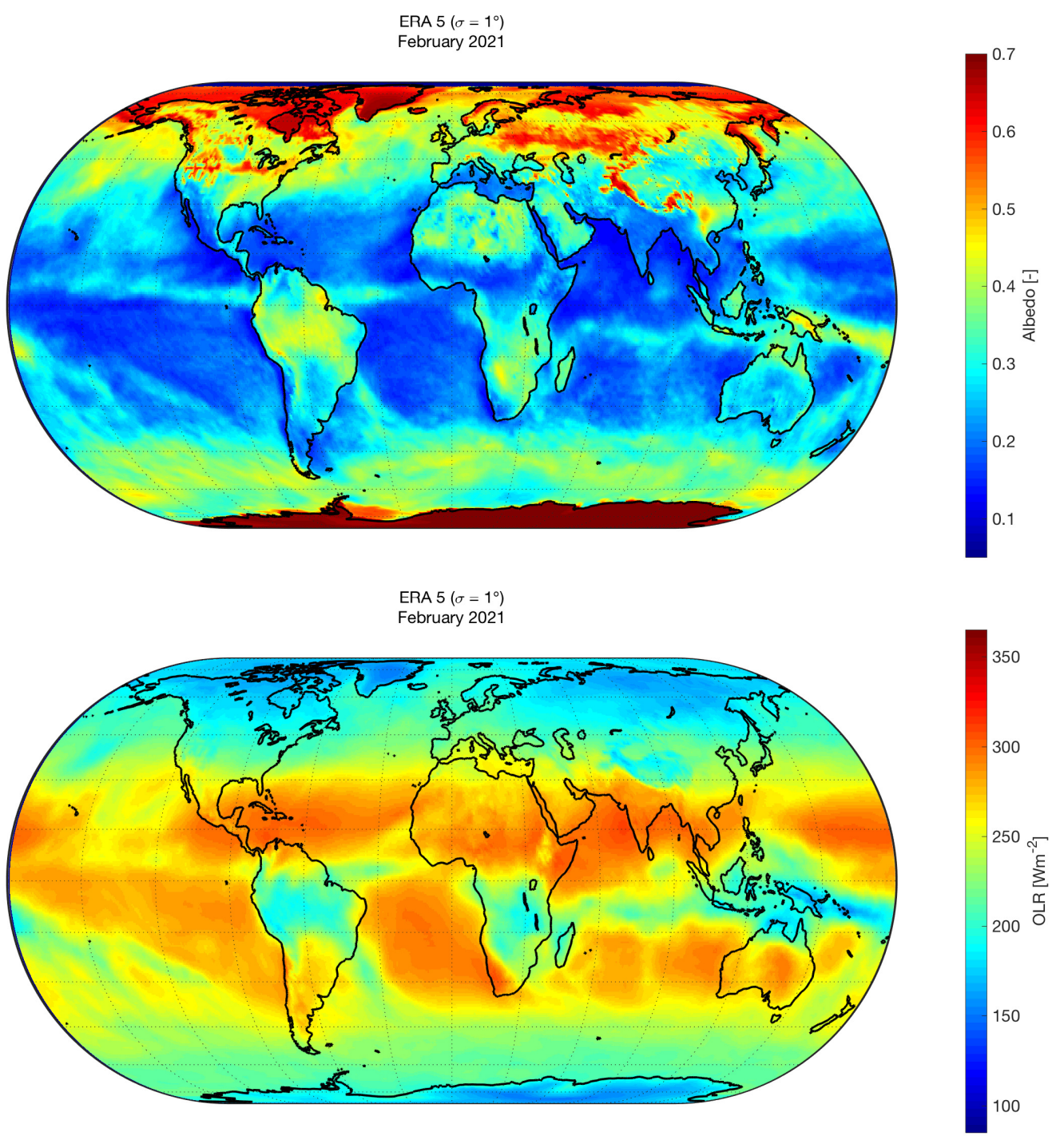

Figure 9. (Top) Albedo from ERA 5 during the month of February 2021. (Bottom) OLR from ERA 5 during the month of February 2021. 
Albedo is computed by the ratio of the difference of the incident shortwave radiation and the net shortwave radiation by the incident shortwave radiation. Surfaces that reflect a lot of the light falling on them have a high albedo. Surfaces that don't reflect much light have a low albedo. Albedo values vary across the globe with latitude. At the poles, it can be greater than 0.7 in some areas. This is a result of the lower solar angle present at the poles but also the higher presence of fresh snow, ice, and smooth open water. In the tropics $\left(23.5^{\circ} \mathrm{N}\right.$ to $\left.23.5^{\circ} \mathrm{S}\right)$, albedo is between 0.1 to 0.4 . OLR values vary also across the globe with latitude, and is primarily sensitive to near-surface and atmospheric temperatures, the air humidity, and the presence of clouds, which are related to the intensity of convective activity as well as the latitude and altitude dependence of the variability. Low OLR values $\left(<200 \mathrm{Wm}^{-2}\right)$ associated with deep atmospheric convection are found over the equatorial land masses, Amazon basin, and in the western equatorial Pacific. These maps highlight the finesse of the observations (notably in equatorial Atlantic ocean). These details will disappear when increasing the FOV, and consequently degrade the spatial resolution. Considering the ground track of UVSQ-SAT in February 2021 (with same spatio-temporal observations), it is possible to reconstruct new albedo and OLR maps from the ERA 5 model. The impact of the FOV (related to $\sigma$ ) also has a significant effect on the map reconstructions. Figure 10 shows the reconstructed map of the albedo for the ERA 5 model for $\sigma=1^{\circ}$ and $\sigma=180^{\circ}$. Figure 11 shows the reconstructed map of the OLR for the ERA 5 model for $\sigma=1^{\circ}$ and $\sigma=180^{\circ}$.

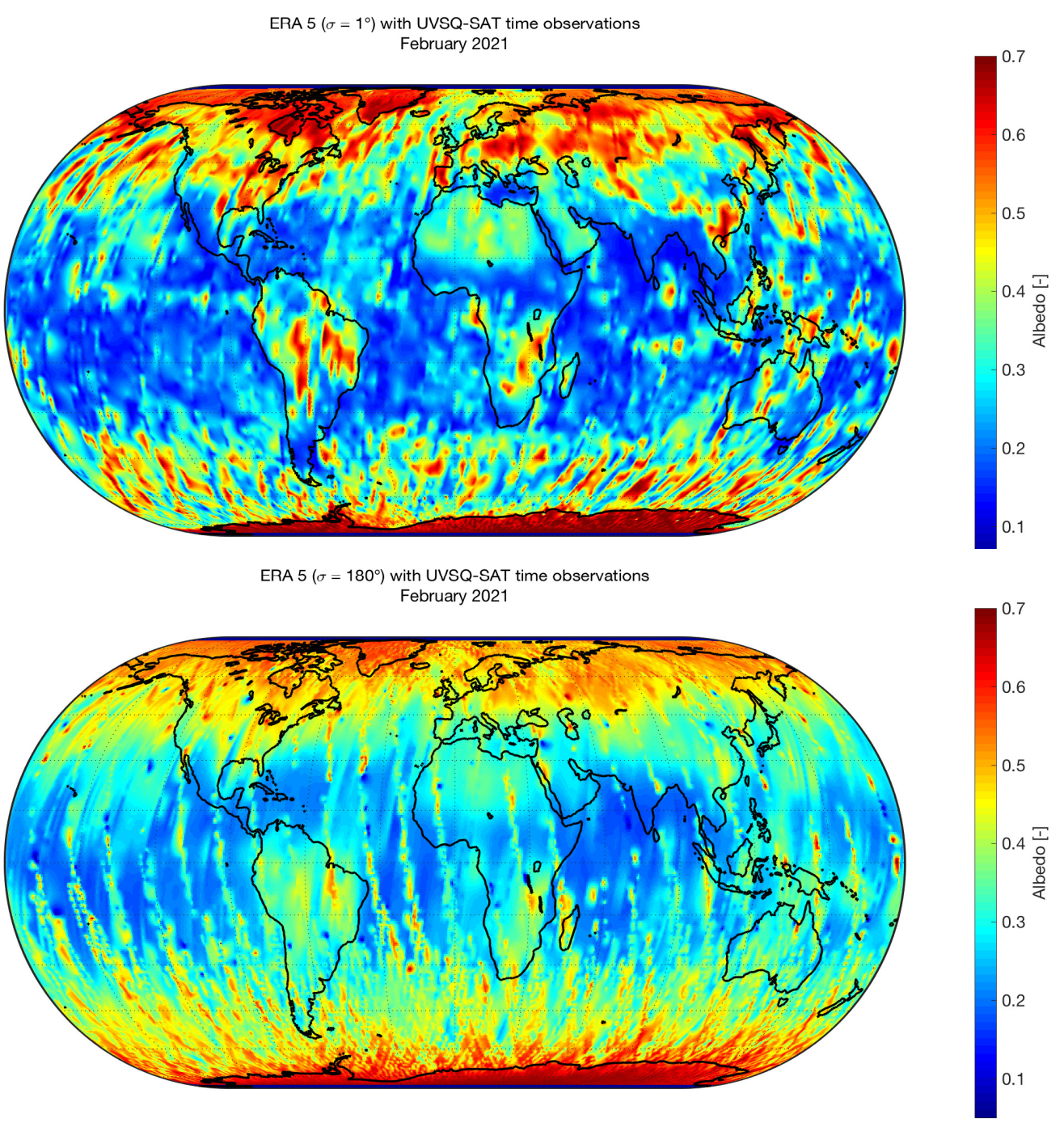

Figure 10. (Top) Albedo (ERA 5) during the month of February 2021 from same observation than UVSQ-SAT $\left(\sigma=1^{\circ}\right)$. (Bottom) Albedo (ERA 5) from same observation than UVSQ-SAT $\left(\sigma=180^{\circ}\right)$. 
These reconstructed maps are slightly different from the ERA 5 monthly averaged data (Figure 9). The selected data (same spatio-temporal resolution than UVSQ-SAT) related to the ground track of the satellite (Figure 7) have an impact on the reconstructed maps (clearly visible for albedo when increasing $\sigma$ ). Low OLR values in the equatorial Atlantic ocean disappear (Figure 11 Bottom) due to the lack of data and low spatial resolution.

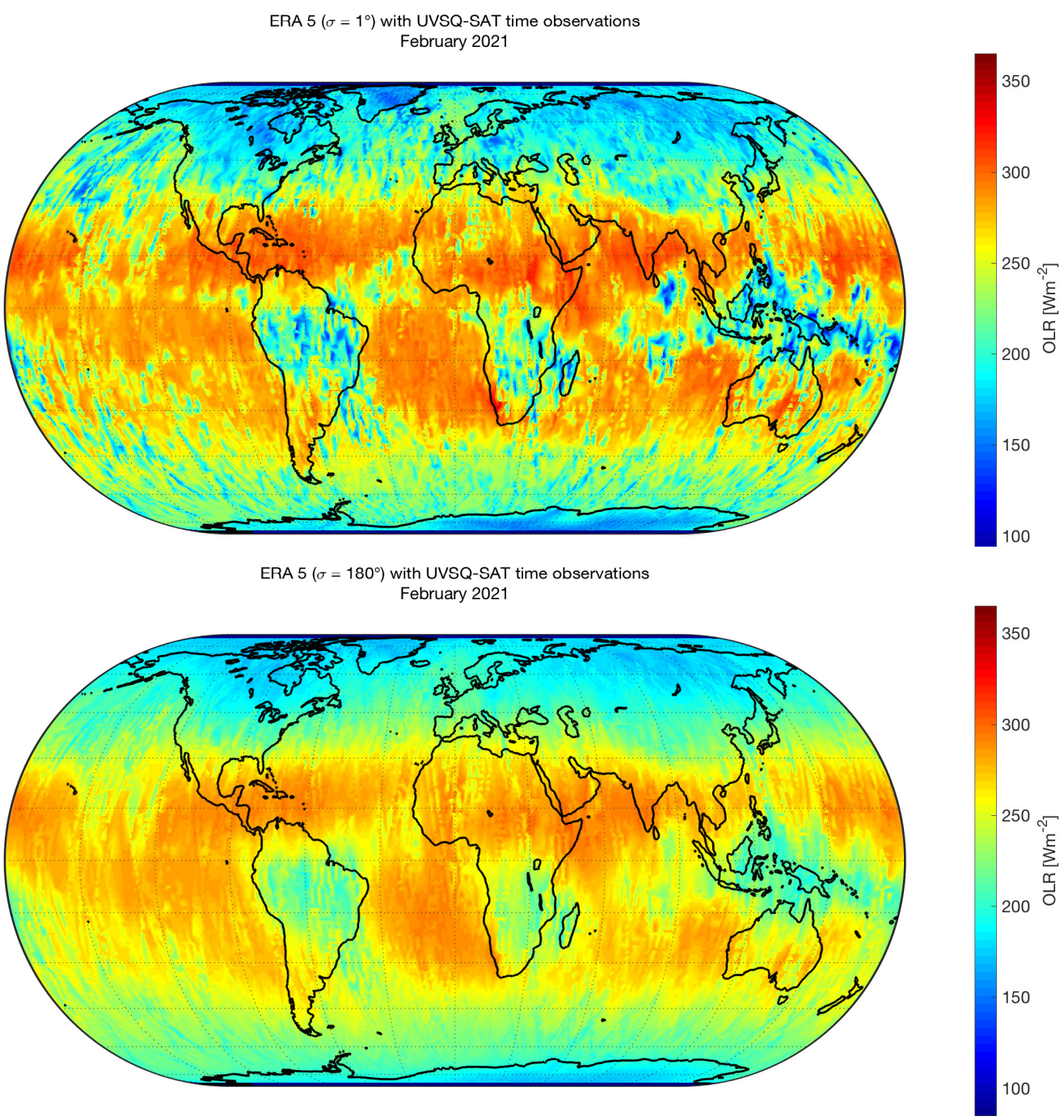

Figure 11. (Top) OLR (ERA 5) during the month of February 2021 from same observation than UVSQ-SAT $\left(\sigma=1^{\circ}\right)$. (Bottom) OLR (ERA 5) from same observation than UVSQ-SAT $\left(\sigma=180^{\circ}\right)$.

These simulations show the importance for doing the right comparisons between model and observations (same spatio temporal resolution). That's why, other methods are under investigation to improve the finesse of the details to be restored (albedo and OLR maps). In a second approach, it is planned to use the spherical harmonics method developed by Gristey et al. (2017) [17] to reconstruct the maps of the quantities of interest. The value measured by the satellite $F_{\text {sat }}$ is expressed as follows (Equation (13)):

$$
F_{\text {sat }}(\lambda, \theta)=\sum_{l=0}^{L} \sum_{m=0}^{l}\left[C_{l m} \bar{Y}_{l m}^{C}(\theta, \lambda)+S_{l m} \bar{Y}_{l m}^{S}(\theta, \lambda)\right]+e
$$

with $\theta, \lambda$, the colatitude and longitude of the point considered, $\bar{Y}_{l m}^{C}$ and $\bar{Y}_{l m}^{S}$, the spatially integrated spherical harmonics, $C_{l m}, S_{l m}$, the coefficients that we seek to determine and $e$, the error on the measurements. The coefficients $C_{l m}$ and $S_{l m}$ are then estimated by the least squares method. 


\section{UVSQ-SAT First Observations}

Since February 2021, UVSQ-SAT has been measuring, among other things, solar radiation reflected from the Earth and OLR. UVSQ-SAT does not have an active attitude control system. Therefore, it is equipped with several photodiodes and ERS sensors on all sides to perform scientific measurements. Six photodiodes allow to measure both the TSI and the OSR. The albedo is obtained from these measurements considering the TSI as known and measured with other space-based instruments. Twelve ERS sensors allow to measure the TSI, the OSR and the OLR with a wide FOV in a complete hemisphere. The whole absorbed radiations generate temperature gradients on the ERS thermopile which delivers a voltage proportional to the absorbed flux (Equation (1)). Six of the twelve ERS thermopiles are coated with carbon nanotubes in order to absorb all incident radiation from short to long wavelengths (absorption very close to 1). The BRDF of the carbon nanotubes coating was measured with a goniophotometer. The optical coating shows a weak angular dependence. During eclipses, these detectors measure only the OLR. Out of eclipses, the carbon nanotube-based thermopiles measure the TSI, the OSR, and the OLR. There are also six ERS thermopiles, which are coated with optical solar reflectors to mainly measure the OLR.

\subsection{UVSQ-SAT Time Series}

From the measurements made by the different sensors of UVSQ-SAT and using the instrumental equations described in Sections 3.1.1 and 3.1.2, we obtain the evolution of the albedo and the OLR. Figure 12a shows the evolution of the signal measured by the six photodiodes over time (example given for about 2 observation orbits). The eclipse periods are clearly identifiable by the absence of signal. Figure $12 \mathrm{~b}$ shows a good agreement between the calculated albedo and thus modeled from the ERA 5 data using different FOV (referred as $\sigma$ values). On Figure 12c, the satellite temperatures evolve in accordance with the UVSQ-SAT thermal qualification (Figure 4). These temperature and the signal measured by the ERS sensors allow to retrieve the OLR (Figure 12d), which is directly observed during eclipse periods. Once again, the measured OLR fluxes show a good agreement with the modeled ones from the ERA 5 data.
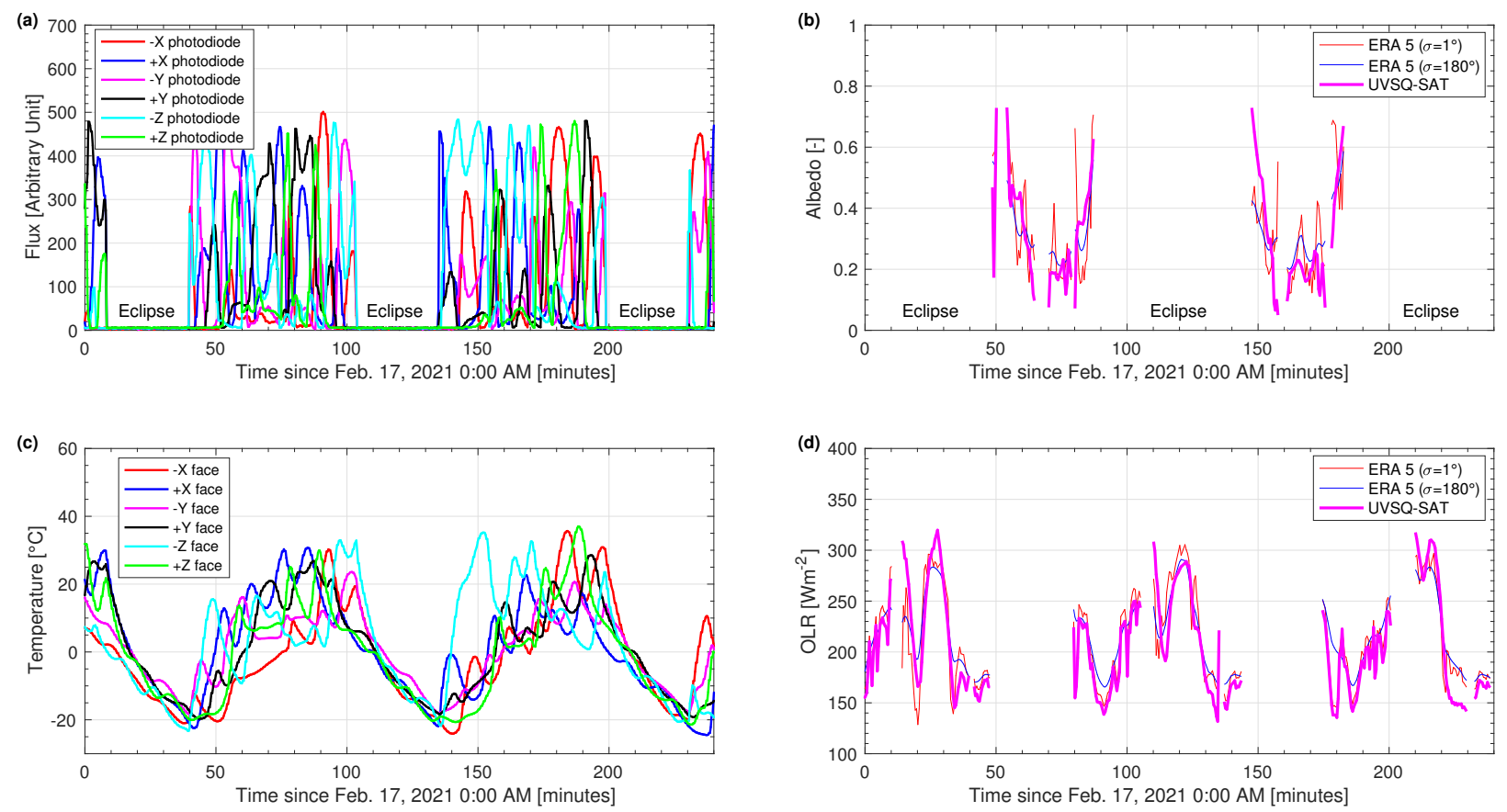

Figure 12. (a) Evolution of the measured flux by the six photodiodes during a given period. (b) Evolution of the albedo modeled from the ERA 5 data and for UVSQ-SAT observations. (c) Evolution of the satellite temperatures. (d) Evolution of the OLR. 
The accumulation of OLR measurement points over time for the Earth's location points will provide averages to characterize the evolution of the OLR over time. It is important to have new record of the OLR to bring new lights and to continue historical records (Figure 6). A long term continuous record is possible using a new disruptive space observational system based on UVSQ-SAT pathfinder.

\subsection{UVSQ-SAT Maps Reconstruction}

UVSQ-SAT maps reconstruction (albedo and OLR) are based on UVSQ-SAT time series. Currently, the reconstruction of each map is based on a Gaussian function whose parameters are defined by the satellite altitude and its FOV. In addition, a method based on a deep learning (DL) algorithm has been developed to obtain the satellite attitude in order to better determine the Earth's albedo and OLR [18]. The satellite attitude can also be reconstructed from the measurements of an inertial measurement unit (IMU). UVSQ-SAT is equipped with a gyrometer to measure angular velocity, an accelerometer to measure gravity and linear acceleration, and a magnetometer to measure the Earth's magnetic field. The magnetometer allows to measure the direction and the intensity of the magnetic field. The objective is to gather these inertial and magnetic data in order to reconstruct the attitude of the satellite. Figure 13 shows the intensity of the Earth's magnetic field measured by UVSQ-SAT thanks to its different sensors.

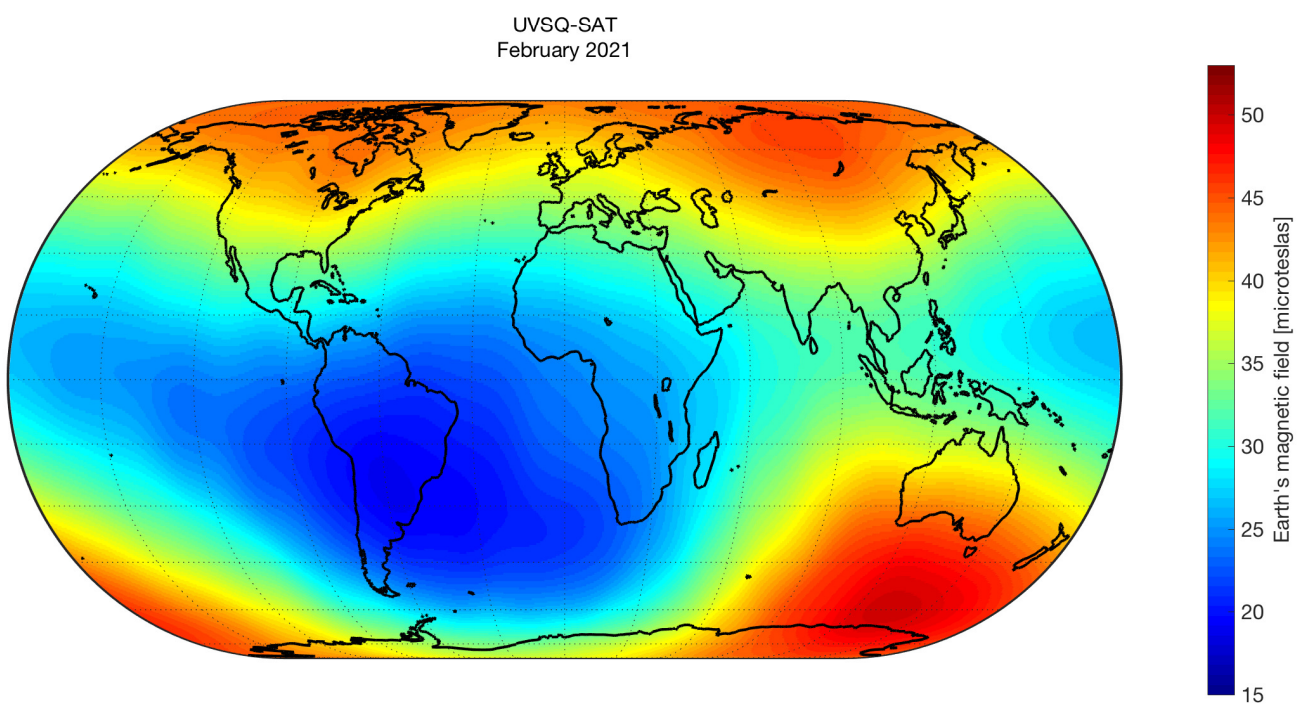

Figure 13. Earth's magnetic field intensity measured by UVSQ-SAT instruments. The calibrations are being validated to consolidate the absolute measurement bias.

Regarding the albedo and OLR, preliminary results have been obtained by applying the methods described in this study and in Meftah et al. (2020) [1]. Figure 14 shows a reconstructed map of the Earth's albedo (February 2021) obtained from UVSQ-SAT instruments. The albedo due to the atmosphere comes from Rayleigh backscattering in the short wavelength range and from clouds, which contribute about two thirds of the total albedo. The effect of the TSI at the TOA is stronger in the tropics. The high albedo at polar latitudes due to the presence of snow and ice on the ground has an important effect. This is of interest to follow this evolution over time. There are also local differences due to the albedo of cloudy regions (intertropical zone of convergence) or the ground (Sahara). The albedo of the ground depends strongly on its nature, it can be very high for fresh snow (about 0.75 ) and low for vegetation (below 0.2 ). The albedo of the ocean remains very low and of the order of 0.1 . It depends on the distribution of waves. 


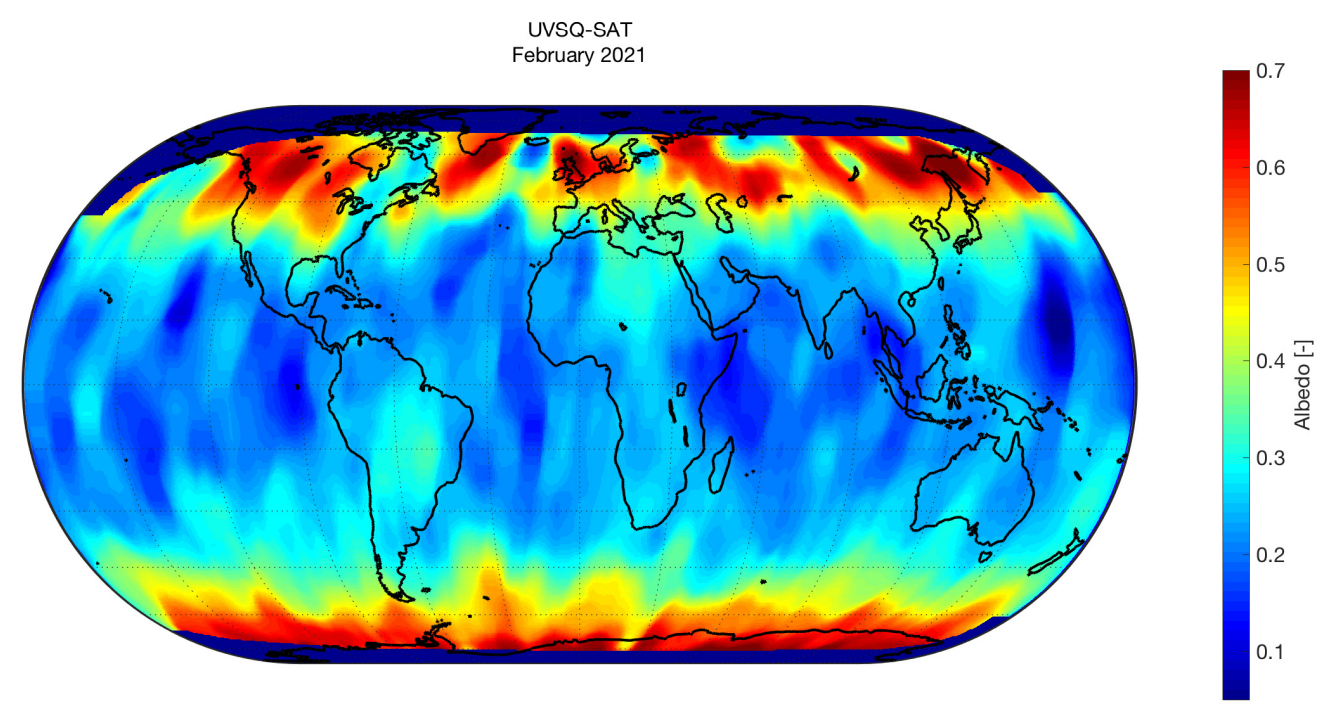

Figure 14. Earth's albedo at TOA measured by UVSQ-SAT instruments. The dark blue areas correspond to regions without data.

The OLR at the TOA (Figure 15) also has a latitude dependence. The high latitudes are cooler and emit less infrared radiation. The humid tropical regions are clearly visible. In tropical and equatorial regions, the weak radiation emerging at the TOA at long wavelengths is due to the presence of clouds at high altitudes. These clouds absorb the radiation emitted by the Earth's surface. Therefore, as they are cold, they emit a weak outgoing radiation in space.

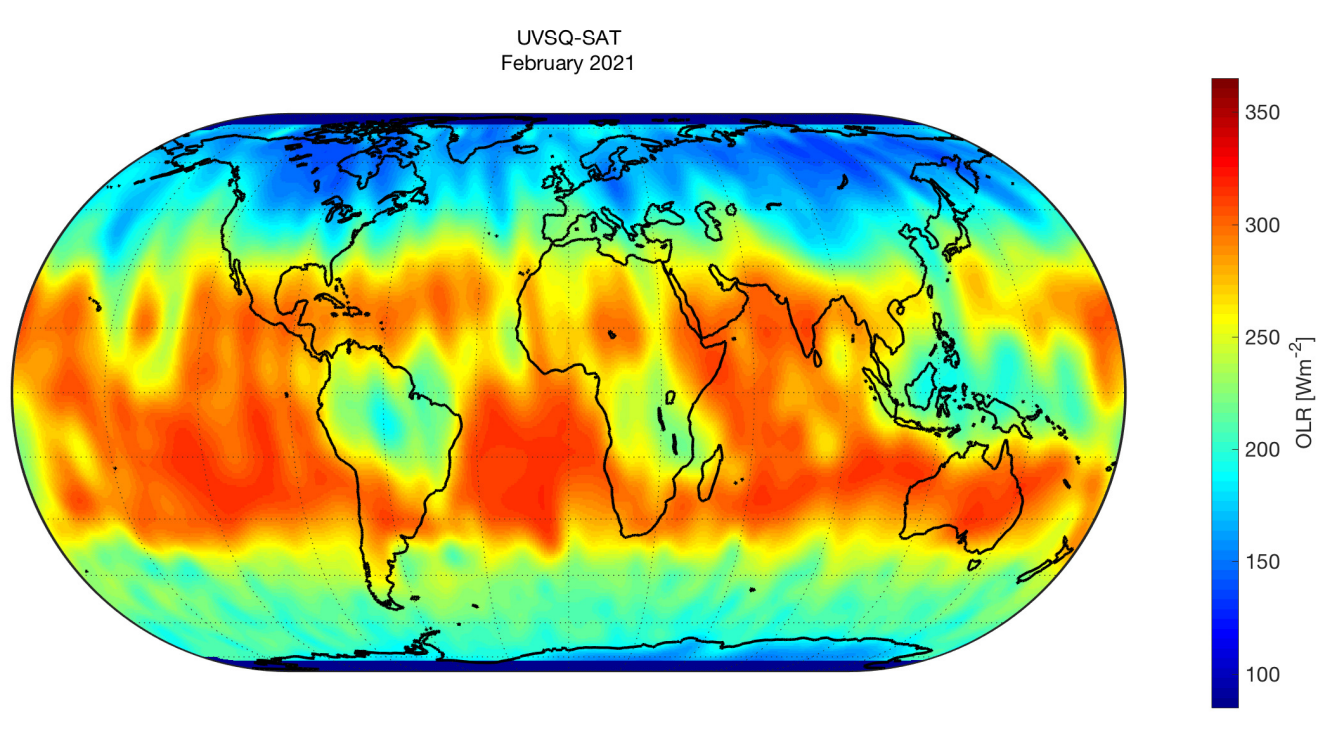

Figure 15. OLR at the TOA measured by UVSQ-SAT instruments.

UVSQ-SAT maps (Figures 14 and 15) look identical to the maps obtained with the ERA 5 model using the same observations time series (Figures 10 and 11). The UVSQ-SAT sensors used have wide fields of view. The reconstructions maps are associated with wide fields of view.

\section{Perspectives-Toward a Satellites Constellation for Climate Studies}

The objective of the UVSQ-SAT mission is to validate the principle of several miniaturized technologies at the highest level of technological maturity (TRL 9) in order to be able to accurately measure the EEI using a constellation (homogeneous and or heterogeneous) 
of small satellites. It will be necessary to combine simple instruments (wide FOV and wide wavelength band) with more complex instruments (narrow FOV and using on-board calibration sources to follow the evolution of the degradation of the instruments in orbit). The Radiometer Assessment using Vertically Aligned Nanotubes (RAVAN) 3U CubeSat mission [19] develops a similar approach to demonstrate technologies for the measurement of Earth's radiation budget in order to implement a satellites constellation.

Gristey et al. (2017) [17] showed how a constellation of satellites with broadband radiometers can provide both spatial and temporal information to accurately measure the ERB. Wiscombe and Chiu (2013) [20] proposed a constellation of space-based instruments, capable of overcoming sampling limitations and providing global and diurnal measurements of the Earth's outgoing radiation with accuracy. With advances in technology and miniaturization of instruments, it is possible to envision a constellation of small satellites capable of measuring outgoing and variable terrestrial radiation from the Earth. The "UVSQ-SAT" concept is fully integrated in this approach and shows a way.

With a single low-orbiting satellite (UVSQ-SAT), it is possible to obtain "satisfactory" mappings of the OSR and the OLR at the TOA only every month (with a loss of short time-scale information). Meftah et al. (2020) [1] show that a constellation of at least 50 satellites is necessary to have at least a daily mapping. Indeed, a constellation of at least 50 satellites is a prerequisite to capture spatio-temporal variations (every three hours and ideally a resolution of a few $\mathrm{km}$ ). This would be fundamental data to validate climate models. These data are used to validate models and the magnitude of energy imbalances at the TOA. The model mesh size is about 100-200 km. The Baseline Surface Radiation Network (BSRN) and Atmospheric Radiation Measurements Program network (ARM) can be used on local and regional scale models. They are mainly used in the calibration and use of spatial data. These data are of primary importance to help validate spatial data and numerical model simulations.

UVSQ-SAT and its future constellation (Figure 16) address the same scientific theme as Far-infrared Outgoing Radiation Understanding and Monitoring (FORUM), but from a completely different angle. FORUM will be put into orbit in 2026. It will measure the Earth's infrared emission spectrum at high spectral resolution. Libera (named for the daughter of agricultural goddess Ceres in ancient Roman mythology) represents another important mission to measure the Earth's outgoing radiative energy. The Libera instrument will fly on National Oceanic and Atmospheric Administration (NOAA) operational Joint Polar Satellite System-3 (JPSS-3) satellite, which is scheduled to launch by December 2027.
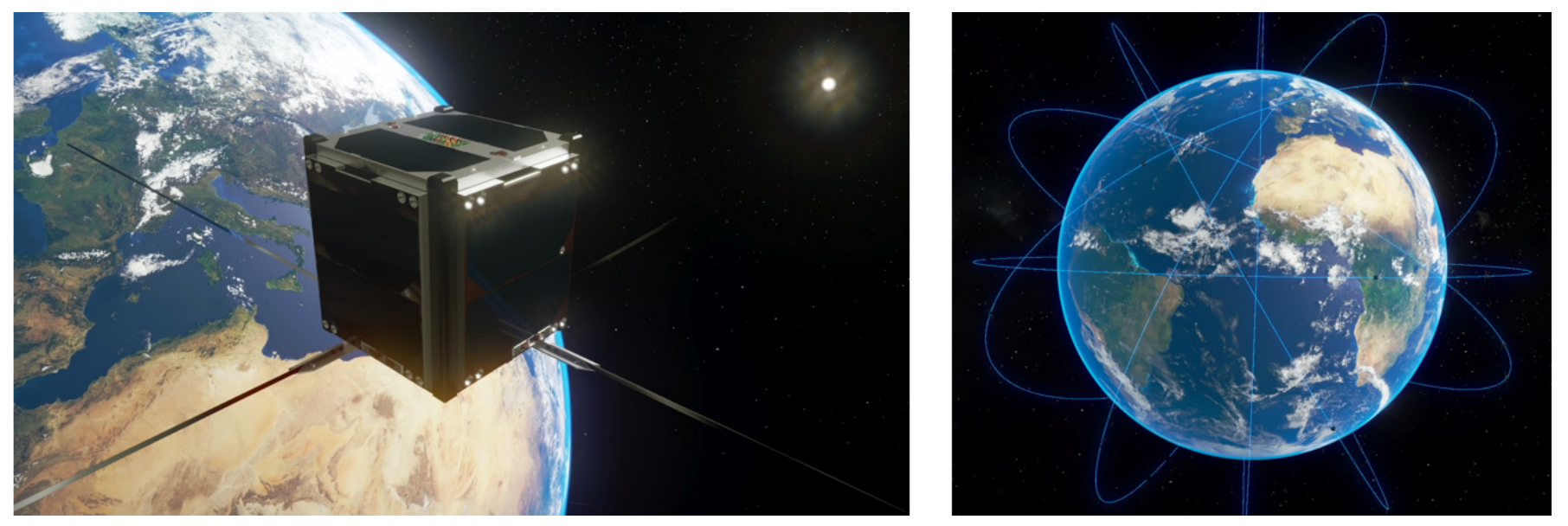

Figure 16. UVSQ-SAT and its potential future satellites constellation named Terra-F.

\section{Conclusions}

The UVSQ-SAT mission was launched in January 2021. Since February 2021, the satellite has been observing the Earth and the Sun. The first results were obtained using 
the methods described by Meftah et al. (2020) [1]. These results are very encouraging and clearly show that small satellites represent a fast method to answer key scientific questions. In the era of NewSpace, i.e., an era benefiting from technological advances in miniaturization and reasonable costs to access space, this mission clearly shows that a constellation of small satellites dedicated to the measurement of the EEI is feasible.

At a time when the climate emergency is obvious and the signals of global warming of the Earth are largely above the level of natural variability, one of the greatest challenges remains the difficulty of obtaining adequate funding for research and especially for missions dedicated to the study of climate (EEI at the TOA, spectral solar irradiance, vertical temperature profile, ozone, aerosols, etc.). These missions must rely on the implementation of satellites constellation to ensure sufficient spatial and temporal coverage. Satellites constellation dedicated to the study of climate and science are now a matter of course [21]. The UVSQ-SAT prototype opens the way to a potential Terra-F constellation composed of 50 small satellites with the necessary performance to meet the scientific need.

Other solutions to measure the EEI are possible with two "traditional" satellites placed at the L1 and L2 Lagrange points in order to make measurements of our planet on the illuminated and non-illuminated portions. The main goal is to make measurements of the EEI at the TOA and its variability in time in order to detect any long-term global trend with a stability of at least $\pm 0.2 \mathrm{Wm}^{-2}$ per decade but also to be able to obtain spatial resolutions of a few tens of $\mathrm{km}$ and temporal resolutions of three hours with an accuracy of a few $\mathrm{Wm}^{-2}$. These measurements must be performed on wide wavelength bands.

Today, it is becoming increasingly clear that small satellites are not only a fast way to answer key scientific questions but also contribute qualitatively to scientific research.

Author Contributions: Conceptualization, M.M. (Mustapha Meftah), T.B., C.D., A.H., P.K., A.F., S.B., S.A., E.B., L.D., J.-L.E., P.G. (Patrick Galopeau), P.G. (Pierre Gilbert), L.L., A.S., A.-J.V., P.L., X.A., O.H.F.d., A.M., J.-P.C., F.B., M.M. (Michel Mahé) and C.M.; Data curation, M.M. (Mustapha Meftah), T.B., C.D., A.H., A.F. and N.C.; Formal analysis, M.M. (Mustapha Meftah), T.B., C.D., A.H. and A.F.; Funding acquisition, M.M. (Mustapha Meftah); Investigation, M.M. (Mustapha Meftah), E.B., P.L. and N.C.; Methodology, M.M. (Mustapha Meftah), T.B., C.D., A.H., P.K., A.F., S.B., S.A., L.D., J.-L.E., P.G. (Patrick Galopeau), P.G. (Pierre Gilbert), L.L., A.S., A.-J.V. and X.A.; Project administration, M.M. (Mustapha Meftah); Resources, M.M. (Mustapha Meftah); Software, M.M. (Mustapha Meftah), T.B., C.D., A.H., P.K. and A.F.; Supervision, M.M. (Mustapha Meftah); Validation, M.M. (Mustapha Meftah), T.B. and C.D.; Visualization, M.M. (Mustapha Meftah), T.B., A.H. and A.F.; Writing—original draft, M.M. (Mustapha Meftah), T.B., C.D., A.H., P.K., A.F., S.B., S.A., E.B., L.D., J.-L.E., P.G. (Patrick Galopeau), P.G. (Pierre Gilbert), L.L., A.S., A.-J.V., P.L., N.C., X.A., O.H.F.d., A.M., J.-P.C., F.B., M.M. (Michel Mahé) and C.M.; Writing—review and editing, M.M. (Mustapha Meftah), T.B., C.D. and A.H. All authors have read and agreed to the published version of the manuscript.

Funding: This research was mainly funded by Centre National de la Recherche Scientifique (CNRS, France), Université de Versailles Saint-Quentin-en-Yvelines (UVSQ, France), and Agence Nationale de la Recherche (ANR, France). This work was supported by the Programme National Soleil Terre (PNST, France) of CNRS/INSU (France) co-funded by Centre National d'Études Spatiales (CNES, France) and Commissariat à l'énergie atomique (CEA, France).

Acknowledgments: The UVSQ-SAT team acknowledges support from CNRS, UVSQ, the Sorbonne Université (SU, France), the Université Paris-Saclay (France), the Office National d'Etudes et de Recherches Aérospatiales (ONERA, France), CNES, the Laboratory for Atmospheric and Space Physics (LASP, USA), the National Central University (NCU, Taiwan), and the Nanyang Technological University (NTU, Singapore). The authors acknowledge the multiple and very fruitful discussions about the Earth's energy imbalance which took place during the conception and writing-up of the unsuccessful European Space Agency EArth enerGy imbalance ExploreR (EAGER) proposal. The authors thankfully acknowledge the Ministère de l'Enseignement supérieur, de la Recherche et de l'Innovation (MESRI, France) for their support. Finally, the authors would like to thank the referees for their valuable comments which helped to improve the manuscript.

Conflicts of Interest: The authors declare no conflict of interest. 


\section{References}

1. Meftah, M.; Damé, L.; Keckhut, P.; Bekki, S.; Sarkissian, A.; Hauchecorne, A.; Bertran, E.; Carta, J.P.; Rogers, D.; Abbaki, S.; et al. UVSQ-SAT, a pathfinder cubesat mission for observing essential climate variables. Remote Sens. 2020, 12, 92. [CrossRef]

2. Twiggs, R.J. Space system developments at Stanford University: From launch experience of microsatellites to the proposed future use of picosatellites. In Proceedings of the Small Payloads in Space, San Diego, CA, USA, 7 November 2000; Horais, B.J., Twiggs, R.J., Eds.; Volume 4136, pp. 79-86. [CrossRef]

3. Puig-Suari, J.; Schoos, J.; Turner, C.; Wagner, T.; Connolly, R.; Block, R.P. CubeSat developments at Cal Poly: The standard deployer and PolySat. In Proceedings of the Small Payloads in Space, San Diego, CA, USA, 7 November 2000; Horais, B.J., Twiggs, R.J., Eds.; 2000; Volume 4136, pp. 72-78. [CrossRef]

4. Xie, S.P.; Kosaka, Y. What caused the global surface warming hiatus of 1998-2013? Curr. Clim. Chang. Rep. 2017, 3, 128-140. [CrossRef]

5. $\quad$ von Schuckmann, K.; Palmer, M.D.; Trenberth, K.E.; Cazenave, A.; Chambers, D.; Champollion, N.; Hansen, J.; Josey, S.A.; Loeb, N.; Mathieu, P.P.; et al. An imperative to monitor Earth's energy imbalance. Nat. Clim. Chang. 2016, 6, 138-144. [CrossRef]

6. Loeb, N.G.; Manalo-Smith, N.; Su, W.; Shankar, M.; Thomas, S. CERES top-of-atmosphere Earth radiation budget climate data record: Accounting for in-orbit changes in instrument calibration. Remote Sens. 2016, 8, 182. [CrossRef]

7. Allan, R.P.; Liu, C.; Loeb, N.G.; Palmer, M.D.; Roberts, M.; Smith, D.; Vidale, P.L. Changes in global net radiative imbalance 1985-2012. Geophys. Res. Lett. 2014, 41, 5588-5597. [CrossRef] [PubMed]

8. Trenberth, K.E.; Fasullo, J.T.; Von Schuckmann, K.; Cheng, L. Insights into Earth's energy imbalance from multiple sources. J. Clim. 2016, 29, 7495-7505. [CrossRef]

9. Boyer, T.; Domingues, C.M.; Good, S.A.; Johnson, G.C.; Lyman, J.M.; Ishii, M.; Gouretski, V.; Willis, J.K.; Antonov, J.; Wijffels, S.; et al. Sensitivity of global upper-ocean heat content estimates to mapping methods, XBT bias corrections, and baseline climatologies. J. Clim. 2016, 29, 4817-4842. [CrossRef]

10. Cheng, L.; Trenberth, K.E.; Fasullo, J.; Boyer, T.; Abraham, J.; Zhu, J. Improved estimates of ocean heat content from 1960 to 2015. Sci. Adv. 2017, 3, e1601545. [CrossRef] [PubMed]

11. Kiehl, J.T.; Trenberth, K.E. Earth's annual global mean energy budget. Bull. Am. Meteorol. Soc. 1997, 78, 197-208. [CrossRef]

12. Stephens, G.L.; Li, J.; Wild, M.; Clayson, C.A.; Loeb, N.; Kato, S.; L'Ecuyer, T.; Stackhouse, P.W.; Lebsock, M.; Andrews, T. An update on Earth's energy balance in light of the latest global observations. Nat. Geosci. 2012, 5, 691-696. [CrossRef]

13. Trenberth, K.E.; Fasullo, J.T. Tracking Earth's Energy. Science 2010, 328, 316-317. [CrossRef] [PubMed]

14. Hansen, J.; Sato, M.; Kharecha, P.; von Schuckmann, K. Earth's energy imbalance and implications. Atmos. Chem. Phys. 2011, 11, 13421-13449. [CrossRef]

15. Von Schuckmann, K.; Cheng, L.; Palmer, M.D.; Hansen, J.; Tassone, C.; Aich, V.; Adusumilli, S.; Beltrami, H.; Boyer, T.; CuestaValero, F.J.; et al. Heat stored in the Earth system: Where does the energy go? Earth Syst. Sci. Data 2020, 12, $2013-2041$. [CrossRef]

16. Pachauri, R.K.; Allen, M.R.; Barros, V.R.; Broome, J.; Cramer, W.; Christ, R.; Church, J.A.; Clarke, L.; Dahe, Q.; Dasgupta, P.; et al. Climate Change 2014: Synthesis Report. Contribution of Working Groups I, II and III to the Fifth Assessment Report of the INTERGOVERNMENTAL Panel on CLIMATE CHANGE; IPCC: Geneva, Switzerland, 2014.

17. Gristey, J.J.; Chiu, J.C.; Gurney, R.J.; Han, S.C.; Morcrette, C.J. Determination of global Earth outgoing radiation at high temporal resolution using a theoretical constellation of satellites. J. Geophys. Res. Atmos. 2017, 122. [CrossRef]

18. Finance, A.; Meftah, M.; Dufour, C.; Boutéraon, T.; Bekki, S.; Hauchecorne, A.; Keckhut, P.; Sarkissian, A.; Damé, L.; Mangin, A. A New Method Based on a Multilayer Perceptron Network to Determine In-Orbit Satellite Attitude for Spacecrafts without Active ADCS Like UVSQ-SAT. Remote Sens. 2021, 13, 1185. [CrossRef]

19. Swartz, W.; Lorentz, S.; Papadakis, S.; Huang, P.; Smith, A.; Deglau, D.; Yu, Y.; Reilly, S.; Reilly, N.; Anderson, D. RAVAN: CubeSat Demonstration for Multi-Point Earth Radiation Budget Measurements. Remote Sens. 2019, 11, 796. [CrossRef] [PubMed]

20. Wiscombe, W.; Chiu, C. The next step in Earth radiation budget measurements. In AIP Conference Proceedings; American Institute of Physics: College Park, MD, USA, 2013; Volume 1531, pp. 648-651.

21. Baker, D.N.; Chandran, A.; Chang, L.; Macdonald, M.; Meftah, M.; Millan, R.M.; Park, J.H.; Kumar, P.; Price, C.; von Steiger, R.; et al. An International Constellation of Small Spacecraft. Space Res. Today 2020, 208, 23-28. [CrossRef] 